\title{
Ultrasmall cationic superparamagnetic iron oxide nanoparticles as nontoxic and efficient MRI contrast agent and magnetic-targeting tool
}

This article was published in the following Dove Press journal:

International Journal of Nanomedicine

28 July 2015

Number of times this article has been viewed

\author{
Mayara Klimuk Uchiyama' \\ Sergio Hiroshi Toma' \\ Stephen Fernandes de Paula \\ Rodrigues ${ }^{2}$ \\ Ana Lucia Borges Shimada ${ }^{2}$ \\ Rodrigo Azevedo Loiola ${ }^{2}$ \\ Hernán Joel Cervantes \\ Rodríguez ${ }^{3}$ \\ Pedro Vitoriano Oliveira ${ }^{4}$ \\ Maciel Santos Luz ${ }^{4}$ \\ Said Rahnamaye Rabbani ${ }^{3}$ \\ Henrique Eisi Toma' \\ Sandra Helena Poliselli \\ Farsky² \\ Koiti Araki' \\ 'Laboratory of Supramolecular \\ Chemistry and Nanotechnology, \\ Department of Fundamental \\ Chemistry, Institute of Chemistry, \\ ${ }^{2}$ Laboratory of Experimental \\ Toxicology, Department of Clinical \\ and Toxicological Analysis, Faculty of \\ Pharmaceutical Sciences, ${ }^{3}$ Magnetic \\ Resonance Laboratory, Department \\ of General Physics, Institute of \\ Physics, ${ }^{4}$ Analysis and Research Group \\ in Spectrometry, Department of \\ Fundamental Chemistry, Institute of \\ Chemistry, University of Sao Paulo, \\ Sao Paulo, SP, Brazil
}

Correspondence: Koiti Araki Laboratory of Supramolecular Chemistry and Nanotechnology, Department of Fundamental Chemistry, Institute of Chemistry, University of Sao Paulo, Av Prof Lineu Prestes, 748, Butanta 05508-000, Sao Paulo, SP, Brazil

$\mathrm{Tel}+55$ । I 309। 38।9

$\mathrm{Fax}+55$ II 38155640

Email koiaraki@iq.usp.br

\begin{abstract}
Fully dispersible, cationic ultrasmall ( $7 \mathrm{~nm}$ diameter) superparamagnetic iron oxide nanoparticles, exhibiting high relaxivity $\left(178 \mathrm{mM}^{-1} \mathrm{~s}^{-1}\right.$ in $\left.0.47 \mathrm{~T}\right)$ and no acute or subchronic toxicity in Wistar rats, were studied and their suitability as contrast agents for magnetic resonance imaging and material for development of new diagnostic and treatment tools demonstrated. After intravenous injection (10 mg/kg body weight), they circulated throughout the vascular system causing no microhemorrhage or thrombus, neither inflammatory processes at the mesentery vascular bed and hepatic sinusoids (leukocyte rolling, adhesion, or migration as evaluated by intravital microscopy), but having been spontaneously concentrated in the liver, spleen, and kidneys, they caused strong negative contrast. The nanoparticles are cleared from kidneys and bladder in few days, whereas the complete elimination from liver and spleen occurred only after 4 weeks. Ex vivo studies demonstrated that cationic ultrasmall superparamagnetic iron oxide nanoparticles caused no effects on hepatic and renal enzymes dosage as well as on leukocyte count. In addition, they were readily concentrated in rat thigh by a magnet showing its potential as magnetically targeted carriers of therapeutic and diagnostic agents. Summarizing, cationic ultrasmall superparamagnetic iron oxide nanoparticles are nontoxic and efficient magnetic resonance imaging contrast agents useful as platform for the development of new materials for application in theranostics.
\end{abstract}

Keywords: cationic USPIOs, MRI, contrast agent, magnetic targeting, in vivo toxicity, intravital microscopy

\section{Introduction}

Recently, many efforts have been focused on the development of materials for theranostics, ${ }^{1}$ by combining in them diagnostic and treatment capability. Superparamagnetic iron oxide nanoparticles (SPIOs) were clinically approved as magnetic resonance imaging (MRI) contrast agents and have been proposed as platform for development of materials combining targeting, tracking, and hyperthermia treatment capability. For example, Das et $\mathrm{al}^{2}$ synthesized a multimodal and theranostic nanoagent, which combines magnetic and receptor-specific targeting, magnetic resonance/optical imaging, and $\mathrm{pH}$-sensitive drug release all in one system. It was based on ultrasmall superparamagnetic iron oxide (USPIOs) nanocore modified with a hydrophilic, biocompatible, and biodegradable coating of $\mathrm{N}$-phosphonomethyl iminodiacetic acid (PMIDA) that was further modified with rhodamine B, folic acid (FA), and methotrexate. Another interesting feature is the enhanced biological activity of anticancer drugs when bonded to magnetic nanoparticles, improving their antitumor efficiency. Durdureanu-Angheluta et $\mathrm{al}^{3}$ reported a dramatic reduction of cell viability (to approximately $10 \%$ ) upon exposure of HepG2 cells to Rhein-loaded, heparin-coated magnetic nanoparticles, indicating the high potentiality of hybrid magnetite nanoparticles in cancer therapy 
as compared with the free drug. Lee et $\mathrm{al}^{4}$ observed similar effect for magnetic nanoparticles loaded with mitoxantrone in targeted therapy against prostate cancer. Another application that has been pursued is the use of a magnetic field gradient to hold or guide SPIOs to a desired place where they can release the load of molecules. ${ }^{5,6}$

Sivakumar et al ${ }^{7}$ prepared magnetic nanoparticles, coated with bacterial exopolysaccharides mauran and gellan gums, exhibiting excellent biocompatibility and low cellular cytotoxicity, demonstrating therapeutic potential for application in magnetic hyperthermia, as well as targeted drug delivery, and cancer cell imaging. SPIOs can also be used as thermoseeds capable of absorbing and converting electromagnetic energy, instead of oscillating magnetic fields, into heat warming up their immediate neighborhood. ${ }^{8,9}$

In fact, the high magnetization, large surface area, and possibility of chemical functionalization of SPIOs surface with multiple targeting (peptides, proteins, aptamers), therapeutic (chemotherapeutics, antibiotics, anti-inflammatories), and signaling molecules (fluorescent dyes, radioactive agents, and other reporters), can be explored to tailor their properties for specific applications. ${ }^{10}$

Finally, it is well known that superparamagnetic nanoparticles produce extremely large local magnetic field gradients shortening the longitudinal $\left(\mathrm{T}_{1}\right)$ and especially the nuclear magnetic dipoles transverse relaxation times $\left(\mathrm{T}_{2}\right)$, as well as the free induction decay time $\left(\mathrm{T}_{2}{ }^{*}\right)$ of NMR signals. In fact, the sensitivity achievable with SPIOs is much higher than that possible with gadolinium complexes commercialized as MRI contrast agents. However, the efficiency is strongly dependent on composition, morphology, particle size, size distribution, and degree of crystallinity ${ }^{11}$ - parameters directly influencing the superparamagnetic behavior. Therefore, understanding their relationship with the intrinsic relaxation times of nuclear spins and controlling them is important to improve the performance of SPIOs derivatives for MRI application.

In this context, a good control on the synthesis and surface functionalization of those nanoparticles is essential to optimize fundamental physicochemical properties, ${ }^{12}$ the biological activity and fate. ${ }^{13}$ Thus, the surface coverage and hydrophilic/hydrophobic balance should be carefully controlled for in vivo applications, in order to ensure appropriate colloidal stability in biological fluids. In addition, small nanoparticles with narrow size distribution and high colloidal stability as well as high relaxivity are desirable.

Toxicity, which seems to depend on size, shape, chemical composition, charge, and agglomeration state of nanoparticles, is another important issue that should be addressed before their use in biomedical applications. ${ }^{14}$ In fact, many efforts have been carried out to evaluate the biocompatibility and possible adverse effects of SPIOs. For example, $\mathrm{Wu}$ et $\mathrm{al}^{15}$ determined the biodistribution, clearance, and biocompatibility of oleic acid-Pluronic layer coated SPIOs (core diameter of $11 \mathrm{~nm}$ ). They did not cause long-term changes in liver enzymes levels or induce oxidative stress in male Sprague-Dawley rats, and were completely eliminated from the organism ${ }^{3}$ weeks after intravenous (IV) administration. On the other hand, Marcu et al ${ }^{16}$ targeted a MCF-17 breast cancer cell line delivering iron oxide nanoparticles loaded with Violamycine B1, an anthracycline antibiotic that enhanced cellular uptake activity and cell death. Sun et $\mathrm{l}^{17}$ showed that toxicity depends more strongly on the surface coating than the amount of iron oxide present in the cell. Also, SPIOs coated with amino or carboxylate groups were shown to be nontoxic against a mouse brain microvessel endothelial cell line (bEnd.3) and primary culture of mouse astrocytes and neurons, at concentrations below $100 \mu \mathrm{g} / \mathrm{mL}$. At higher doses, neurons were more sensitive to aminoSPIOs, whereas astrocytes showed to be more vulnerable to carboxylated-SPIOs. More recently, the biodistribution and fate of polyvinylalcohol microbubbles loaded with SPIOs ${ }^{18}$ were studied by MRI in Sprague-Dawley rats during 6 weeks demonstrating to cluster in the lungs, and then in pulmonary, hepatic, and splenic macrophages, while the cytoplasmic iron concentration was increased in lungs and other organs.

Magnetite nanoparticles-based MRI contrast agents such as Resovist (SHU-555A, Bayer Schering Pharma AG, Leverkusen, Germany), Supravist (SHU-555C, Bayer Schering Pharma AG), Sinerem (AMI-227, Guerbet, Villepinte, France), and Endorem (AMAG Pharmaceuticals Inc., Waltham, Ma, USA) are being or were commercialized until recently in the US and Europe as more effective and safer diagnostic MRI contrast agents than gadolinium-based compounds. However, they are quite expensive and many of them were withdrawn from the market. Therefore, it is very important to develop new cheaper SPIOs to increase competitiveness and popularize their use. Kumar et a ${ }^{19}$ demonstrated a synthetic strategy for preparation of 8-10 nm large SPIOs $\left(T_{2}\right.$ relaxivity $R_{2}=222 \mathrm{mM}^{-1} \mathrm{~s}^{-1}$ in $4.7 \mathrm{~T}$ ) by thermal decomposition, followed by biocompatibilization through exchange of the oleate coating by a citric acid/2-bromo-2methylpropionic acid layer and final bioconjugation with FA. This FA-SPIOs (folic acid conjugated SPIOs) conjugate was preferentially uptake by FA receptor-positive cells increasing the intracellular iron content but exhibiting no cytotoxicity. Accordingly, here we describe on the high potentiality of 
ultrasmall, $7 \mathrm{~nm}$ large, ethylamine-functionalized, and fully dispersible cationic USPIOs (cat-USPIOs) as MRI contrast agents exhibiting no in vivo acute/subchronic toxicity and enhanced efficiency $\left(R_{2}=178 \mathrm{mM}^{-1} \mathrm{~s}^{-1}\right.$ in $\left.0.47 \mathrm{~T}\right)$, as platform for development of theranostics.

\section{Materials and methods Synthesis of cationic USPIOs}

Cat-USPIOs were prepared by thermo decomposition ${ }^{20,21}$ of an iron(III) complex in a high boiling point solvent, in the presence of hydrophilic protecting groups, according to the method described by Caruntu et al. ${ }^{22}$ After 1 hour at $210^{\circ} \mathrm{C}$, the color of the reaction mixture changed from bright orange to black, as expected for the formation of magnetite nanoparticles. The reaction mixture was cooled to $90^{\circ} \mathrm{C}$ and then $0.5 \mathrm{~mol}$ of $o$-phosphorylethanolamine was added per mol of $\mathrm{Fe}_{3} \mathrm{O}_{4}$, while stirring for an additional hour. The ethylamine-functionalized cat-USPIOs was isolated as a black solid by cooling the reaction mixture to room temperature and separating it with a magnet. The solid was washed with ethanol twice and with a $1: 1 \mathrm{v} / \mathrm{v}$ mixture of ethanol and acetone three times, and dried in a desiccator under vacuum for 24 hours. Due to the presence of hydrophilic groups on the surface, ethylamine-functionalized cat-USPIOs are readily dispersible in water without using an ultrasound bath or other high-energy dispersion tools.

The morphology and average particle size was evaluated by transmission electron microscopy (TEM) using a 200 kV Phillips CM200 transmission electron microscope. The samples were prepared spreading a drop of cat-USPIOs dispersion on a copper grid covered with a carbon film. The average particle size distribution and zeta potential were evaluated by dynamic light scattering (DLS) using a Microtrac ${ }^{\circledR}$ Nanotrac 252 equipment.

Relaxivity measurements of water molecule protons were performed in a Bruker Minispec mq20 spectrometer, using CPMG (Carr-Purcell Meiboom Gill) pulse sequence (magnetic field $=0.47 \mathrm{~T}$ ), by diluting a concentrated catUSPIOs dispersion in deionized water to get samples with $2,000,1,000,500,250,100,50,20,10,5$, and $2 \mathrm{mg} \cdot \mathrm{L}^{-1}$ of $\mathrm{Fe}_{3} \mathrm{O}_{4}$. The temperature was kept constant at $25^{\circ} \mathrm{C}$ using a thermostatic bath. The relaxation time $\mathrm{T}_{2}$ was determined by multi-exponential fitting of the decay curves using the Multiexp software, and the relaxivity estimated from the reciprocal of $\mathrm{T}_{2}$ versus $\mathrm{Fe}_{3} \mathrm{O}_{4}$ concentration plot (Table 1). This was determined by inductively coupled plasma optical emission spectroscopy measurements carried out in an iCAP 6500 Duo (Thermo Fisher Scientific, Cambridge, UK) equipment with axial plasma viewing.
Table I Relaxivity of ethylamine-functionalized cat-USPIOs as compared with commercial SPIOs used as MRI contrast agents

\begin{tabular}{llll}
\hline Sample & Main use & Size $(\mathbf{n m})$ & Relaxivity $\left(\mathrm{mM}^{-1} \mathbf{s}^{-1}\right)$ \\
\hline Cationic USPIOs & $\mathrm{T}_{2}$ & 7 & $\mathrm{R}_{2}=178(0.47 \mathrm{~T})$ \\
Resovist $^{\circledR a}$ & $\mathrm{~T}_{2}$ agents & 62 & $\mathrm{R}_{2}=188(0.94 \mathrm{~T})$ \\
Endorem $^{\circledR b}$ & $\mathrm{~T}_{2}$ agents & 58 & $\mathrm{R}_{2}=107(0.47 \mathrm{~T})$ \\
Feridex $^{\circledR c}$ & $\mathrm{~T}_{2}$ agents & $18-24$ & $\mathrm{R}_{2}=35(0.47 \mathrm{~T})$ \\
Sinerem $^{\oplus \mathrm{d}}$ & $\mathrm{T}_{2}$ agents & $17-20$ & $\mathrm{R}_{2}=53(0.47 \mathrm{~T})$ \\
Magnevist $^{\circledR e}$ & $\mathrm{~T}_{1,2}$ agents & Molecular & $\mathrm{R}_{2}=3.9(0.94 \mathrm{~T})$ \\
\hline
\end{tabular}

Notes: Relaxivity is proportional to the applied magnetic field. ${ }^{\mathrm{a} C a r b o x i-d e x t r a n}$ SPIOs SHU-555, 'Dextran SPIOs AMI-25, 'Dextran SPIOs MION 46L, dDextran SPIOs, ${ }^{e}$ Gd-DTPA.

Abbreviations: cat-USPIOs, cationic ultrasmall superparamagnetic iron oxide nanoparticles; MRI, magnetic resonance imaging.

\section{Magnetic resonance imaging in rats}

This study was carried out strictly following the recommendations in the "Guide for the Care and Use of Laboratory Animals of the National Institute of Health" (NIH Publication 8523). The protocol was approved by the Committee of Ethics on Animal Care and Use of Institute of Chemistry of University of Sao Paulo (Protocol number 07/2013), following the recommendations of CONCEA, the Brazilian National Council on Animal Care and Use in Experiments.

Male Wistar rats were used as in vivo model for MRI, magnetic concentration, clearance, and toxicological evaluation. The performance of ethylamine-functionalized cat-USPIOs as MRI contrast agent was evaluated after IV administration of $10 \mathrm{mg} / \mathrm{kg}$ body weight (from now on "mg/ $\mathrm{kg}$ " instead of " $\mathrm{mg} / \mathrm{kg}$ body weight" will be used to improve clarity) dispersed in $1 \mathrm{~mL}$ of acetate buffer $(10 \mathrm{mM}, \mathrm{pH} 4.5)$ containing $50 \mathrm{mM}$ of $\mathrm{NaCl}$, and recording MRI. Cat-USPIOs samples were IV injected, during 10 minutes, through a cannula inserted in the right femoral vein of three ( $\mathrm{n}=3$ ) male Wistar rats (about $200 \mathrm{~g}$ body weight) previously anesthetized with $75 \mathrm{mg} / \mathrm{kg}$ of ketamine and $7.5 \mathrm{mg} / \mathrm{kg}$ of xylazine (Vetbrands, Jacarei, SP, Brazil). All samples for IV administration were prepared just before use by simply redispersing the cat-USPIOs powder in acetate buffer to protonate the ethylamine groups on the surface, facilitating their redispersion in aqueous media. MRI images were collected from about 1 hour up to 28 days after IV administration to confirm their potentiality as contrast agents, monitoring in vivo nanoparticles biodistribution and clearance behavior. Animals were anesthetized with intraperitoneal injection of $75 \mathrm{mg} / \mathrm{kg}$ of ketamine and $7.5 \mathrm{mg} / \mathrm{kg}$ of xylazine just before each MRI scan. All images were registered using a 1.5 T Gyroscan S15 ACSII (Philips Medical Systems, Endovein, the Netherlands) using a $22 \mathrm{~cm}$ diameter surface coil. The images were registered in the coronal direction and the main pulse parameters employed in the experiments are listed in Table 2. 
Table 2 Image sequence parameters used in MRI scanning

\begin{tabular}{ll}
\hline Parameter & Value \\
\hline Image sequence & GRET2* (FFE) \\
Slide thickness & $1 \mathrm{~mm}$ \\
Repetition time & $266 \mathrm{~ms}$ \\
Echo time & $15 \mathrm{~ms}$ \\
Average & 16 \\
FOV & $200 \times 110 \mathrm{~mm}^{2}$ \\
Slide direction & Coronal \\
Slide number & Between 40 and 46 \\
Flip angle & $25^{\circ}$ \\
Image resolution & $256 \times 140$ pixels \\
Scan duration & About 54 minutes \\
\hline
\end{tabular}

Abbreviations: MRI, magnetic resonance imaging; FFE, fast field echo; FOV, field of view.

The possibility of magnetically inducing cat-USPIOs accumulation in a predetermined place can be of great interest to treat localized tumors, atheroma plaques or even brain tumors and stroke. In this case, magnetite nanoparticles functionalized with medicines or therapeutic agents may be concentrated in the affected region, and/or hyperthermia treatment can be carried out. Of course, a high enough force must act on the nanoparticles to overcome the dispersion forces due to the blood flow. In order to evaluate that possibility and determine the effect of cat-USPIOs dose (10 or $50 \mathrm{mg} / \mathrm{kg}$ ) on the contrast and clearance rate, the same experiment described earlier was repeated using two groups of three male Wistar rats $(\mathrm{n}=3)$ while keeping a magnet on the outer side of the left leg thigh for 2 hours after IV injection. This site was chosen because a spontaneous accumulation is not expected in that place and all accumulated cat-USPIOs can be assigned exclusively to a magnetically induced process. After 2 hours, the magnet was removed and MRI collected as soon as possible to monitor the magnetic concentration, clearance, and eventual redistribution of cat-USPIOs as a function of time. MRI images were collected 2 hours, 1, 7, 14, 21, and 28 days after, and 2, 30, 60, 100, and 140 days after administration of 10 or $50 \mathrm{mg} / \mathrm{kg}$ of cat-USPIOs, respectively. A magnet $(\mathrm{NdFeB})$ with $1 \mathrm{~cm}^{2}$ area and maximum magnetic flux density of $0.6 \mathrm{~T}$ was used in the experiment.

\section{Cat-USPIOs in vivo toxicity}

Considering the application of cat-USPIOs as contrast agents for MRI diagnoses and platform for development of magnetic-targeting tools and theranostics, their possible toxic effects were evaluated for the same group of rats used in MRI experiments, by ex vivo laboratorial assays such as dosage of hepatic and renal enzymes, and blood leukocyte profile (leukocyte count). Another set of animals was used for in vivo intravital microscopy analyses of hepatic and mesenteric venules after IV administration, as described ahead. Also, the iron content in urine was monitored in order to study the influence of the amount of cat-USPIOs retained in the body on its clearance.

The magnetic induced concentration of nanoparticles was evaluated administering $10 \mathrm{mg} / \mathrm{kg}$ of cat-USPIOs to two groups of three animals, and comparing the MRI of the experimental and control groups differing just by the presence or absence of a magnet placed on the left thigh for 2 hours, respectively. Two other groups of three rats each (sham control in the absence and presence of magnet in the thigh) were submitted to the same experimental procedures except that $1 \mathrm{~mL}$ of saline $(0.9 \% \mathrm{w} / \mathrm{w}$ of $\mathrm{NaCl}$ in deionized-water) was injected in place of cat-USPIOs dispersion. Those sham controls were not carried out for the experimental group using $50 \mathrm{mg} / \mathrm{kg}$ of cat-USPIOs to avoid sacrificing more animals. Just for the sake of rigor, an experiment was carried out with one rat, but no significant difference was observed as compared with the group using a dose of $10 \mathrm{mg} / \mathrm{kg}$ body weight.

\section{In vivo toxicity by intravital microscopy}

The in vivo toxicity was evaluated after IV administration of $10 \mathrm{mg} / \mathrm{kg}$ of cat-USPIOs to male Wistar rats. This dose was shown to be suitable to evidence their potentiality as MRI contrast agent, as well as to evaluate the magnet-induced concentration of nanoparticles to a specific site. Thus, we looked forward to determine whether the $10 \mathrm{mg} / \mathrm{kg}$ dose could cause any change on microcirculatory parameters, mainly regarding to inflammatory aspects as measured by leukocyte interaction with endothelial cells (rolling, adhesion, and migration), or formation of hemorrhage and thrombus, as well as monitoring its influence on venular diameter. Mesenteric microcirculation was chosen because of the facile visualization of all those parameters at once. Liver microcirculation was observed as well since magnetic resonance images showed major accumulation of cat-USPIOs in that organ.

Prior to organ exposure, the rats were anesthetized by intramuscular injection of $75 \mathrm{mg} / \mathrm{kg}$ of ketamine and $7.5 \mathrm{mg} / \mathrm{kg}$ of xylazine, and a cannula was inserted into the femoral vein to administer the cat-USPIOs, and anesthetic supplementation ( $10 \%$ of the initial dose) as required. The surgical field was shaved and wiped with $70 \% \mathrm{v} / \mathrm{v}$ alcohol for local asepsis. Then, a medial laparotomy was carried out to expose the mesenteric vascular bed, ${ }^{23}$ which was kept hydrated with a $2 \mathrm{~mL} / \mathrm{min}$ flux of Ringer-Locke buffer with gelatin $\left(154 \mathrm{mM} \mathrm{NaCl}, 5.6 \mathrm{mM} \mathrm{KCl}, 2 \mathrm{mM} \mathrm{CaCl} \cdot 2 \mathrm{H}_{2} \mathrm{O}\right.$, $6 \mathrm{mM} \mathrm{NaHCO}_{3}, 5 \mathrm{mM}$ glucose, and $1 \%[\mathrm{w} / \mathrm{v}$ ] gelatin [Synth, 
Diadema, SP, Brazil]). All procedures were carried out on a special transparent platform heated at $37^{\circ} \mathrm{C}$, which allow tissue trans-illumination. All parameters measured by intravital microscopy were evaluated just before (blank, $\mathrm{t}=0$ minutes), soon after ( $\mathrm{t}=0$ minutes), and 30, 60, 90, and 120 minutes after IV administration of $10 \mathrm{mg} / \mathrm{kg}$ of cat-USPIOs dispersion in $1 \mathrm{~mL}$ of $10 \mathrm{mM}$ acetate buffer containing $50 \mathrm{mM}$ of $\mathrm{NaCl}$. The results collected soon after administration of $1 \mathrm{~mL}$ of saline solution were used as control.

The interaction of leukocytes with the endothelial layer of mesenteric venules was evaluated considering the number of rolling and adherent leukocytes on the post-capillary site (15-30 $\mu \mathrm{m}$ diameter, $100 \mu \mathrm{m}$ blood vessel length). Leukocytes moving in the periphery of the axial stream, in contact with the endothelium, were considered to be rolling, and their number determined considering a period of 5 minutes. The number of leukocytes that adhered to the endothelium (stopped at the vessel wall for at least 30 seconds) was determined simultaneously in the same vascular segment. Leukocytes in the exterior within an area of 2,500 $\mu^{2}$ next to the vessels walls were counted as migrated leukocytes.

After studying the mesentery microcirculation, liver was exposed and the venules at the left superior lobe visualized just after IV injection of $0.02 \%$ rhodamine $6 \mathrm{G}$ solution, prepared by diluting in saline $(10 \times)$ a $0.2 \%$ stock solution in DI-water (Sigma-Aldrich, St Louis, MO, USA) just before use. The organ was humidified with Ringer-Locke buffer, and covered with a plastic film for inspection. Leukocyte adhesion to the sinusoids (number of cells stopped at the vessel walls for at least 30 seconds) was determined as a representative measure of inflammatory effects in liver. The average number collected from at least seven sinusoids for each organ per animal is presented.

All animals were sacrificed after experiments by injecting a lethal anesthetic dose (three times higher than regular dose), and death confirmed by monitoring the cardiac and respiratory arrest.

Trans-illuminated images of mesenteric microcirculation were obtained by optical microscopy using an Axioplan II microscope, equipped with $40.0 \times$ Achroplan longitudinal distance objective and numeric aperture of 0.75 (Carl-Zeiss, Jena, Germany, maximum magnification: $400 \times$ ). The same microscopy system equipped with a fluorescence mode accessory, constituted by a mercury HBO 100 lamp and fluorescence filters, was used to capture fluorescent images of rhodamine 6G-labeled leukocytes in hepatic microvessels. Axioplan Neofluar accessory with $10 \times$ longitudinal distance objective and numeric aperture of 0.3 (Carl-Zeiss; maximum magnification: $100 \times$ ) was used. Color images were captured with a charge coupled device color video camera (AxioCam HRc, Carl-Zeiss) connected to a microcomputer, and subsequently analyzed using the AxioVision software (Carl-Zeiss).

\section{Leukocyte count}

Rats were anesthetized with intraperitoneal injection of $75 \mathrm{mg} / \mathrm{kg}$ of ketamine and $7.5 \mathrm{mg} / \mathrm{kg}$ of xylazine, and $1 \mathrm{~mL}$ of blood was collected from the femoral vein with heparin (5,000 UI/mL; Hepamax-S ${ }^{\circledR}$, Blausiegel, Cotia, SP, Brazil) as anticoagulant to perform the leucocyte count. Blood samples were collected just before 2 hours, and 1-4 weeks after administration of cat-USPIOs. Total cell counts were obtained using a hemocytometer (Herka, Berlin, Germany). Differential leucocyte counts were performed on blood smears stained with the Romanowsky stain (Panótico ${ }^{\circledR}$; Laborclin, São José do Rio Preto, SP, Brazil). ${ }^{24}$ The whole blood was used for quantification of the biochemical, enzymatic, and hepatic parameters as described in the following section.

\section{Dosage of hepatic and renal enzymes}

The whole blood plasma was isolated by centrifugation (3,500 rpm, 10 minutes), stored at $-80^{\circ} \mathrm{C}$, and analyzed using a Labmax $240^{\circledR}$ equipment (Labtest, Lagoa Santa, MG, Brazil). Alanine aminotransferase (ALT), aspartate aminotransferase, urea, urine, and plasma creatinine dosages were measured using commercial kits purchased from Labtest ${ }^{\circledR}$, following the methodology provided by the manufacturer.

\section{Iron content in urine}

Urine samples were collected just before performing the MRI scans, by gently compressing the bladder region of anesthetized Wistar rats. Seven samples were collected from each animal and stored at $-80^{\circ} \mathrm{C}$ until analysis, one just before and the remaining from soon after (time zero) until up to 28 days after administration of cat-USPIOs. The total iron content was determined using a graphite furnace atomic absorption spectrometer, model SIMAA- $6000^{\circledR}$ (PerkinElmer Life and Analytical Sciences, Shelton, CT, USA) equipped with a longitudinal Zeeman-effect background corrector, Echelle optical polychromator, standard THGA tube with integrated pyrolytically coated platform, and solid state detector. An iron hollow cathode source lamp was used as light source and the following instrumental parameters were adopted: $\lambda=248.3 \mathrm{~nm}$, lamp current $=20 \mathrm{~mA}$, and slit width $=0.7 \mathrm{~mm}$. An AS-72 autosampler (PerkinElmer) was used to dispense reproducible amounts of the liquid samples 
Table 3 Instrumental parameters and GFAAS heating program for the determination of $\mathrm{Fe}$ in urine

\begin{tabular}{|c|c|c|c|c|}
\hline \multirow[t]{2}{*}{ Step } & Temperature & Ramp & Hold & Ar flow rate \\
\hline & $\left({ }^{\circ} \mathrm{C}\right)$ & (seconds) & (seconds) & (mL/min) \\
\hline Drying I & 110 & 15 & 10 & 250 \\
\hline Drying II & 130 & 2 & 20 & 250 \\
\hline Pyrolysis & 1,200 & 10 & 20 & 250 \\
\hline Atomization & 2,200 & 0 & 5 & $0^{*}$ \\
\hline Cleaning & 2,400 & I & 3 & 250 \\
\hline
\end{tabular}

Note: *Air flow stopped during atomization.

Abbreviation: GFAAS, graphite furnace atomic absorption spectrometer.

into the graphite furnace minimizing sampling error. Argon gas 99.998\% v/v (Air Liquide Brasil, Sao Paulo, SP, Brazil) was used as the protective and carrying gas. The analyses were carried out using $10 \mu \mathrm{L}$ of calibration or sample solution co-injected with $10 \mu \mathrm{L}$ of $20 \mu \mathrm{g}$ of $\mathrm{Pd}\left(\mathrm{NO}_{3}\right)_{2}$ (Sigma-Aldrich) as chemical modifier. Samples were prepared diluting urine ten times with nitric acid $1 \% \mathrm{v} / \mathrm{v}$. A calibration curve was prepared from blank $\left(1 \% \mathrm{v} / \mathrm{v} \mathrm{HNO}_{3}\right)$ to $50 \mu \mathrm{g} / \mathrm{L}$ of $\mathrm{Fe}(\mathrm{III})$ by diluting a standard $1,000 \mathrm{mg} / \mathrm{L}$ solution of Fe(III) (Titrisol $^{\odot}$ Merck, Darmstadt, Germany) in $1 \% \mathrm{v} / \mathrm{v} \mathrm{HNO}_{3}$. The linear correlation was better than 0.999 in that concentration range. The graphite furnace atomic absorption spectrometer heating program used for urine analysis is listed in Table 3.

\section{Statistical analysis}

All data were expressed as average \pm SEM. Statistical differences between the groups were determined by two-way analysis of variance applying the Tukey's post hoc test implemented in Prism 5 software (GraphPad Software, Inc., San Diego, CA, USA). Statistical significance was set at $P<0.05$.

\section{Results and discussion}

Nanomaterials based on iron oxides are interesting for biomedical applications because they exhibit low toxicity, the raw materials are cheap and abundant, and the synthesis is relatively simple. Among all types of naturally occurring iron oxides, magnetite $\left(\mathrm{Fe}_{3} \mathrm{O}_{4}\right)$ and maghemite $\left(\gamma-\mathrm{Fe}_{2} \mathrm{O}_{3}\right)$ are the most important magnetic iron oxide materials used as contrast agents in MRI, and for the development of nanomaterials for diagnostics and therapeutics (theranostics).

Ideally, magnetic nanoparticles for MRI diagnostics should display superparamagnetic behavior, and induce the largest as possible change in $\mathrm{T}_{2}$. Small nanoparticles are advantageous for this purpose because exhibit higher resolving power and colloidal stability, ${ }^{25}$ particularly ultrasmall nanoparticles with average diameter smaller than $10 \mathrm{~nm}$. Furthermore, they must be fully dispersible in water and in biological medium, be biocompatible minimizing any toxic and immunologic response, and should provide binding sites to attach biomolecules such as antibodies and other proteins, carbohydrates, nucleic acids, and peptides on the surface.

Magnetite nanoparticles were prepared by the thermal decomposition method and functionalized with ethylamine groups, making them dispersible in aqueous media. The samples for TEM imaging were prepared dispersing a diluted aqueous suspension on a copper grid covered with a carbon film. In this condition, hydrophilic nanoparticles tend to agglomerate as shown in Figure 1A due to their low affinity for the substrate and formation of hydrogen bonds connecting the cat-USPIOs through the terminal amino groups. Nevertheless, the presence of $6.9 \mathrm{~nm}$ large, rounded, and highly crystalline nanoparticles is easily noticeable. In fact, a characteristic narrow size distribution histogram (Figure 1B) resulted from the analyses of a large enough number of particles (more than a hundred). The high degree of crystallinity is evidenced in the high-resolution TEM image shown in Figure 1C where the characteristic magnetite crystal planes can be seen clearly. Also, a monomodal distribution, with average size of $9.5 \mathrm{~nm}$ and consistent with the profile described earlier (histogram from the TEM image), was obtained by DLS analysis of cat-USPIOs dispersion in water. A somewhat larger average size is expected by this technique since TEM measures only the core size whereas DLS captures the hydrodynamic radius, ie, the sum of the core size and the thickness of the molecular protecting layer, as well as the double electric and solvation layers.

Superparamagnetic magnetite nanoparticles perturb the external magnetic field decreasing the $\mathrm{T}_{2}$ and $\mathrm{T}_{2}{ }^{*}$ relaxation times of nuclear magnetic spins by defocusing the magnetic moment ensemble in the precession plane perpendicular to the external magnetic field. This decreases the local nuclear magnetic resonance time constants and respective MRI signal intensities. Thus, the presence of cat-USPIOs is indicated by hypointense pixels (negative contrast in MRI) in the final image, ie, darkening the regions where they are present in high enough concentrations.

In fact, cat-USPIOs exhibited a very high relaxivity of $178 \mathrm{mM}^{-1} \mathrm{~s}^{-1}$ in $0.47 \mathrm{~T}$, a value almost twice as large as for products available in the market such as Resovist ${ }^{\circledR}$ $\left(94 \mathrm{mM}^{-1} \mathrm{~s}^{-1}\right.$ in $\left.0.47 \mathrm{~T}\right)$ and Endorem ${ }^{\circledR}\left(107 \mathrm{mM}^{-1} \mathrm{~s}^{-1}\right.$ in $\left.0.47 \mathrm{~T}\right)$, as shown in Table 1. The molecular contrast agent gadolinium-DTPA (Magnevist ${ }^{\circledR}, 1.95 \mathrm{mM}^{-1} \mathrm{~s}^{-1}$ in $0.94 \mathrm{~T}$ ), the most popular MRI contrast agent in the world, exhibits a relaxivity 90 times lower than cat-USPIOs. This means that cat-USPIOs is more efficient as contrast agent and 

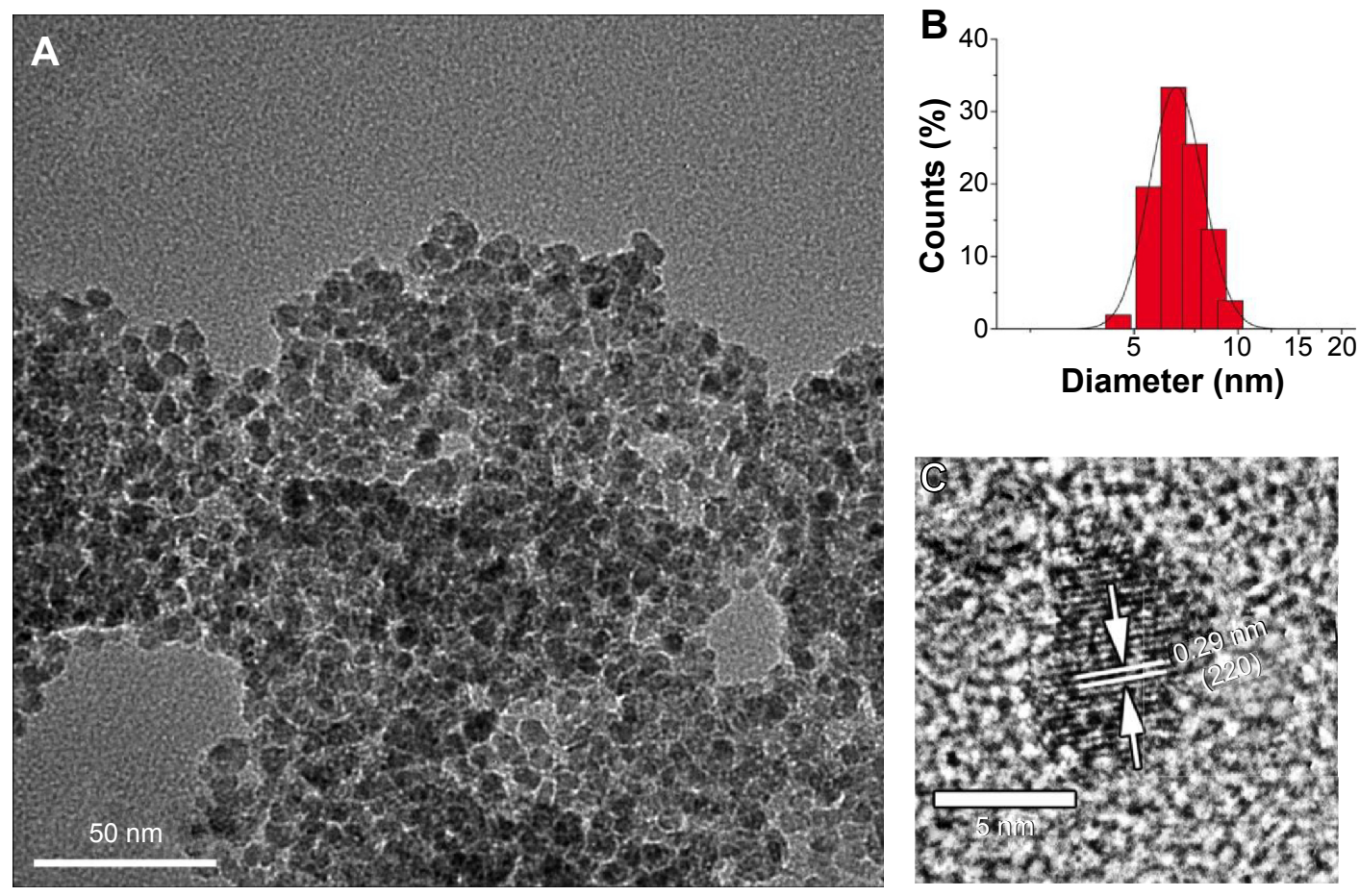

Figure I Transmission electron microscopy image of cat-USPIOs functionalized with aminoethylphosphate (A), the corresponding size distribution histogram (B), and highresolution TEM image showing the characteristic (220) interplanar distances in a magnetite nanocrystal (C) The arrows indicates the interplanar distance of 0.29 nm in the magnetite 220 crystal plane.

Abbreviations: cat-USPIOs, cationic ultrasmall superparamagnetic iron oxide nanoparticles; TEM, transmission electron microscopy

MRI images could be obtained with much smaller and safer doses.

A typical sequence of MRI images of a rat is shown in Figures 2 and 3 . Notice in the control slice that the kidneys (yellow circles in Figure 2A), and also liver and spleen (yellow rectangle in Figure 3), appear as bright regions. The lower lateral region of abdominal cavity appears as a darker region due to the presence of air in between or inside organs. Thus, intestines and lungs appear as black areas due to the air inside. However, after injection of cat-USPIOs, there is an increase of dark areas in the upper abdominal cavity as they concentrate in the kidneys (Figure 2A), liver, and also possibly in the spleen (Figure 3), as described for other SPIOs. ${ }^{13,26,27}$ Nevertheless, no other organs seem to concentrate magnetite nanoparticles. The injection was carried out through the cannulated femoral vein, slowly for 10 minutes, to avoid any damage caused by fast injection or exceedingly high local concentration of magnetite nanoparticles.

Figure 2A shows a strong negative contrast in the renal cortex (yellow circles) 2 hours after injection of $50 \mathrm{mg} /$ $\mathrm{kg}$ of cat-USPIOs as a consequence of their uptake due to renal filtration function, but it starts to become brighter after 24 hours indicating a relatively rapid clearance from that organ. This effect is quantitatively shown in Figure $2 \mathrm{~B}$ where the average normalized density of white pixels at kidneys are depicted as a function of time, showing the decrease of magnetite nanoparticles to about half of its initial concentration after 24 hours. However, the MRI signal intensity is a relative value. Thus, the average density of white pixels in the testicles was used as control to normalize each image, before calculating the average density of white pixels in the kidneys. No evidence of cat-USPIOs accumulation in testicles was found. The error bar is the standard deviation.

The clearance process was shown to be much faster after injection of $10 \mathrm{mg} / \mathrm{kg}$ of cat-USPIOs (Figure S1) indicating that the clearance time is dose-dependent. Kidneys are key organs responsible for the filtration and removal of undesirable substances from blood. The filtration takes place in the nephrons localized in the renal cortex (border region), which clearly appears with significant negative contrast in MRI. The magnetic nanoparticles in the blood are small enough to cross the capillaries of glomerulus into the Bowman's capsule, from where are then sent to the bladder and more or less rapidly eliminated from the body through urine. Our results indicate that cat-USPIOs are able to circulate in the blood vessels until being filtered out and excreted relatively fast from kidneys as demonstrated by MRI studies (Figure 2). 
A

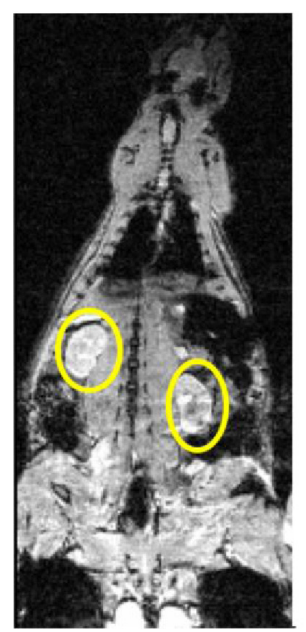

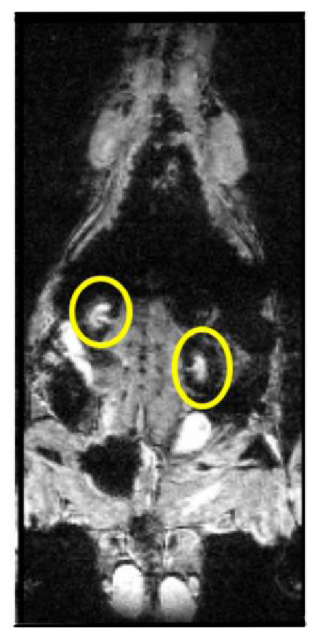

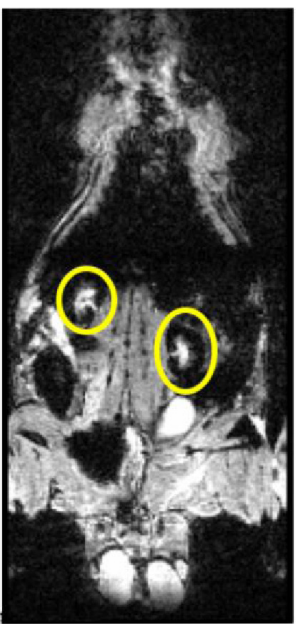

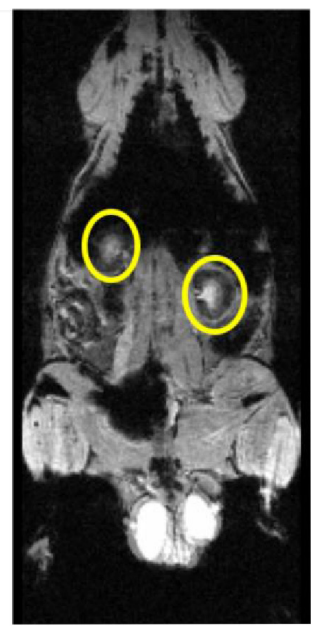

B

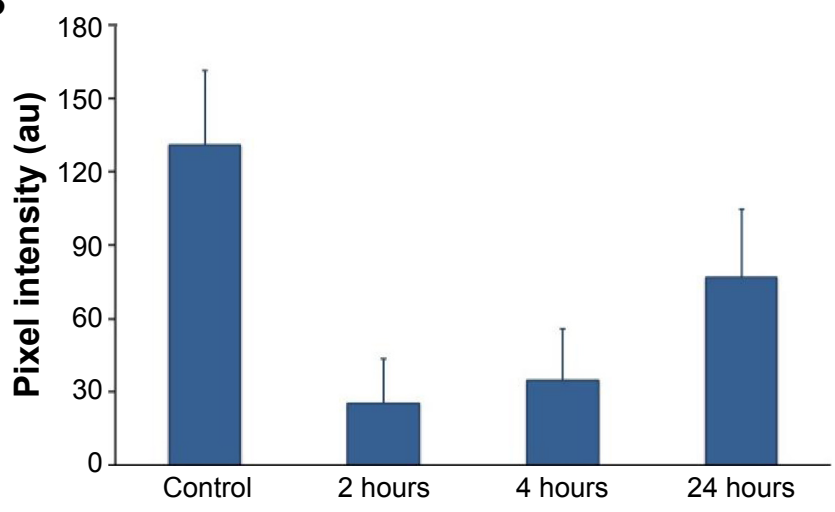

Figure 2 Renal clearance after cat-USPIOs IV administration in male Wistar rat.

Notes: (A) Typical series of MRI images of a Wistar rat after IV administration of $50 \mathrm{mg} / \mathrm{kg}$ of cat-USPIOs, highlighting the variation in the density of white pixels in the kidneys, indicated by yellow circles. The leftmost image was taken before injection of cat-USPIOs (control), and then after 2, 4 , and 24 hours after injection. The head of the rat is pointing up. (B) The average of normalized density of white pixels of four subsequent scans of kidneys as a function of time after IV administration of $50 \mathrm{mg} / \mathrm{kg}$ of cat-USPIOs. The concentration is inversely proportional to the density of white pixels in magnetic resonance signals.

Abbreviations: cat-USPIOs, cationic ultrasmall superparamagnetic iron oxide nanoparticles; MRI, magnetic resonance imaging; IV, intravenous.

\section{Control}

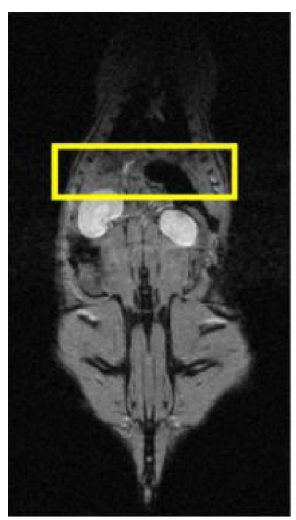

2 days

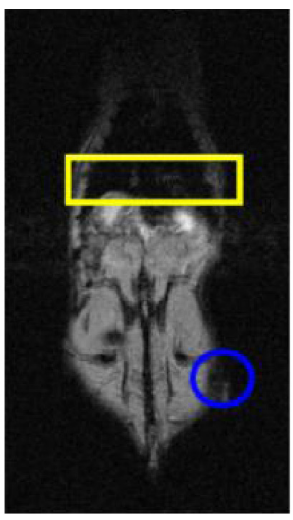

30 days

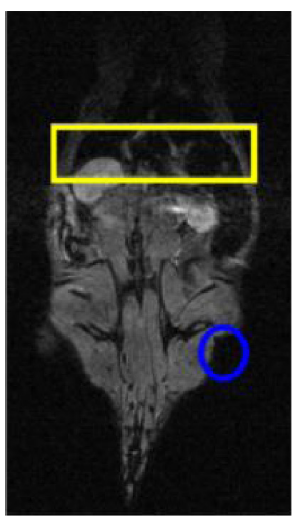

60 days

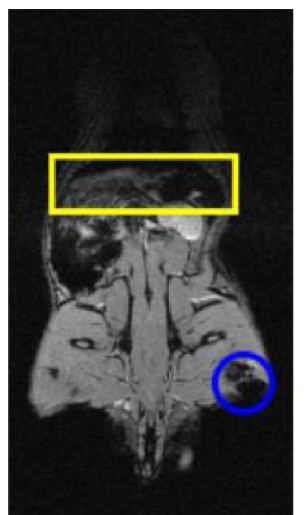

140 days

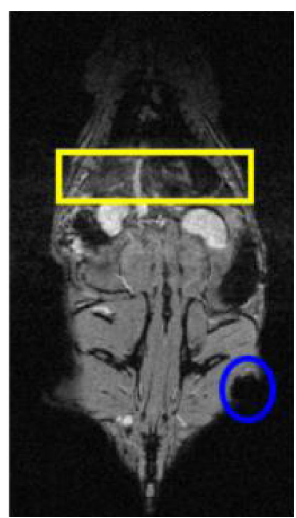

Figure 3 Typical series of MRI images of a Wistar rat treated with $50 \mathrm{mg} / \mathrm{kg}$ of cat-USPIOs as a function of time from zero up to I40 days after IV administration, highlighting the contrast in liver and spleen.

Notes: The negative contrast in the left thigh is due to the accumulation of cat-USPIOs induced by a magnet placed on that local for 2 hours after IV injection. The liver and the spleen are indicated by a yellow rectangle; and a blue circle indicates the negative contrast in the thigh.

Abbreviations: cat-USPIOs, cationic ultrasmall superparamagnetic iron oxide nanoparticles; MRI, magnetic resonance imaging; IV, intravenous. 
On the other hand, about 1-4 months were necessary, respectively, to completely clear 10 (Figure S1) or $50 \mathrm{mg} / \mathrm{kg}$ (yellow rectangles in Figure 3) of cat-USPIOs from the liver, the organ responsible for detoxification of the organism through hepatocytes, that are known to accumulate iron(III) as ferritin or hemosiderin. Even in this unfavorable case, the amount of cat-USPIOs accumulated in the liver after injection of $10 \mathrm{mg} / \mathrm{kg}$ started to show decreasing negative contrast after 2 weeks. However, 60 days were necessary to observe a similar effect in the male Wistar rats that received the highest dose. Before those periods, the concentration of cat-USPIOs was too high such that variations in the negative contrast level could not be noticed. All rats used in the experiments survived and showed no change in their behavior indicating no significant toxicity, good tolerance, and total clearance of magnetite nanoparticles as a function of time even at the very high dose of $50 \mathrm{mg} / \mathrm{kg}$. Proportionally, a $70 \mathrm{~kg}$ human adult would receive $3.5 \mathrm{~g}$ of cat-USPIOs, a dose much higher than that needed in typical MRI diagnoses (typically $0.16-0.24 \mathrm{mg}$ of $\mathrm{Fe}_{3} \mathrm{O}_{4}$, ie, $10-15 \mu \mathrm{mol} \mathrm{Fe} / \mathrm{kg}$ body weight). However, the dosage of $10 \mathrm{mg} / \mathrm{kg}$ is commonly used in MRI studies with rats using SPIOs as contrast agents. ${ }^{8}$

The high and durable negative MRI contrast effect in the liver indicates a much longer retention time of catUSPIOs. That organ is known to stock iron(III) and to produce transferrin, a protein responsible for transporting and distributing iron(III) to all cells in the body as needed, particularly to bone marrow for production of hemoglobin and cytochromes. The paramagnetic properties of the material present in the liver are unequivocally evidenced by the negative contrast. However, there is no clear evidence if magnetite nanoparticles remained as such or were oxidized to maghemite (also superparamagnetic) or dissolved and stored as paramagnetic iron(III) complexes. Nevertheless, the possibility of spontaneous dissolution of nanoparticles generating highly toxic free iron(III) ions can be ruled out considering the low solubility of iron oxides, and also the presence of proteins with many high affinity active sites for bonding iron such as ferritin and hemosiderin. Probably, cat-USPIOs is being uptaken (phagocytosed or endocytosed) by reticuloendothelial system ${ }^{28}$ of liver (mainly endothelial and Kupffer cells) and compartmentalized within lysosomes, where they are broken down due to low $\mathrm{pH}(3.5-4.0)$. The breakdown products as ferritin and hemosiderin exhibit magnetization tenfold lower than cat-USPIOs. ${ }^{29}$ Probably that breakdown process is very slow, thus explaining the maintenance of negative contrast for long periods of time.

The experiment to evidence the magnetic induced accumulation of cat-USPIOs was carried out in a similar way as described earlier for the MRI experiments, except that a magnet was placed on the left thigh of a group of three animals, just before the IV administration of cat-USPIOs through the cannula inserted in the right femoral vein, and kept there for 2 hours. Notice that a negative contrast appeared in the left thigh (blue circle) confirming that the cat-USPIOs flowed throughout the circulatory system, eventually reaching the site where they were magnetically retained (Figure 4). Typically ultrasmall nanoparticles tend to circulate in the blood for longer periods as compared with particles with larger hydrodynamic diameter, ${ }^{29}$ whereas positive charges
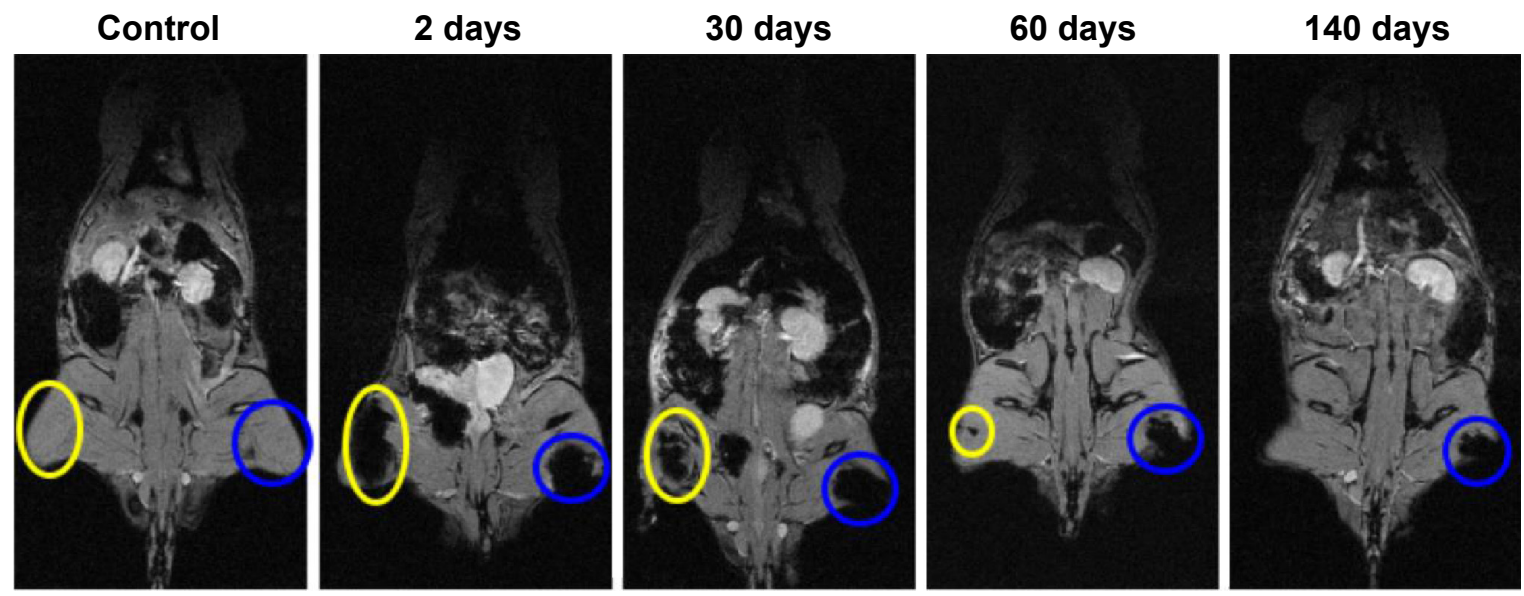

Figure 4 Typical series of MRI images of a Wistar rat treated with $50 \mathrm{mg} / \mathrm{kg}$ of cat-USPIOs as a function of time from zero up to I40 days after IV injection, confirming the magnetically induced accumulation of cat-USPIOs in the left thigh by a magnet placed in the local during 2 hours (blue circle).

Note: The negative contrast shown in the right thigh (yellow circle) is due to the subsequent intramuscular administration of I5 mg/kg of cat-USPIOs.

Abbreviations: cat-USPIOs, cationic ultrasmall superparamagnetic iron oxide nanoparticles; MRI, magnetic resonance imaging; IV, intravenous. 
on nanoparticles tend to induce the opposite effect. ${ }^{30}$ The cat-USPIOs presented high efficiency for the magnet-induced accumulation process, indicating a long enough half-life in the blood.

Two hours after IV injection of $50 \mathrm{mg} / \mathrm{kg}$ of cat-USPIOs with a magnet placed in the left thigh, it was possible to see the accumulation of a large quantity of nanoparticles in that local (blue circles in Figure 4), whose complete clearance took more than 140 days. No spontaneous accumulation is expected at that place as shown by the controls, confirming the magnet-induced concentration of cat-USPIOs at the left tight. For comparison purposes, $15 \mathrm{mg} / \mathrm{kg}$ of cat-USPIOs were injected intramuscularly into the right thigh, as indicated by the negative contrast smear highlighted by a yellow circle. These nanoparticles disappeared after about 60 days whereas the magnetically accumulated nanoparticles were cleared only after more than 140 days, suggesting that the route of administration modify cat-USPIOs interaction with muscle tissues.

The long retention time may be advantageous for treatment purposes, since a single dose of cat-USPIOs is retained longer in the target region without causing significant toxic effects, for example, allowing concomitant treatment by hyperthermia or controlled drug delivery. Also, neutrophil counts must increase in the blood if cat-USPIOs have caused an acute inflammation in muscular tissues of innate origin. However, leukocyte counts remained unchanged indicating there was no inflammatory reaction upon IV administration, as shown in Figure 5. Furthermore, Wistar rats treated with $10 \mathrm{mg} / \mathrm{kg}$ of cat-USPIOs without a magnet placed in the thigh exhibited contrasting liver clearance rates, since the density of white pixels start to increase 14 days after IV administration (Figure S1A) as compared with 7 days in rats with a magnet (Figure $\mathrm{S} 1 \mathrm{~B}$ ). The animals were monitored until up to 28 days, necessary for complete clearance of cat-USPIOs from the organism, as confirmed by MRI. Reproducible results were obtained for all three rats of the group clearly indicating that magnet-induced accumulation of cat-USPIOs in the thigh is decreasing the amount of nanoparticles circulating in the blood, reducing the amount retained by other organs, as expected. Similar effect was observed in the kidneys.

Considering the relatively long clearance time, one cannot believe that the magnetite nanoparticles were simply retained inside veins and vessels, because in this case they would be redispersed by the blood flux as soon as the magnet is removed. Thus, we rather believe that cat-USPIOs crossed the vessel endothelia and penetrated in the adjacent muscle tissues, where they were more strongly retained. In fact, we showed that $15 \mathrm{mg} / \mathrm{kg}$ of cat-USPIOs administrated intramuscularly in right thigh behaved in a similar way as cat-USPIOs concentrated by an external magnetic field, as evidenced by the negative contrast in MRI, taking about 60 days to be cleared (Figure 4). Some literature reports reinforce this hypothesis of nanoparticles crossing blood vessel walls. Thomsen et $\mathrm{al}^{31}$ showed using an in vitro model that SPIOs can pass through blood brain barrier, the most tightly and restrictive vascular barrier in the human body. Also, magnetic nanoparticles were shown to penetrate human umbilical vein endothelial cells in vitro. ${ }^{32}$

Despite the very encouraging results described earlier, the application as MRI contrast agent would be limited if cat-USPIOs exhibits unacceptably high acute toxicity at concentrations typically used for MRI diagnostics. Thus, blood and urine samples, collected from those same groups of animals used for MRI experiments, were analyzed in order to determine the leucocyte counting, the biochemical and hepatic parameters, and the iron content in urine as a function of clearance time, as shown in Figures 5-7.

The number of leukocytes, lymphocytes, and neutrophils (Figure 5) were determined in blood samples collected from six rats soon after finishing the MRI scans, using a hemocytometer. The average number of leukocytes (Figure 5A) remained constant around 5,000 cells per $\mathrm{mm}^{3}$ along 28 days for the control and experimental group of rats $(n=3)$, after administration of saline (vehicle) and cat-USPIOs, respectively. Similarly, no significant statistical difference $(P>0.05)$ could be observed in the number of lymphocyte and neutrophil counts after injection of saline or cat-USPIOs (Figure 5B and C). Therefore, there is no alteration in the number of leukocytes, lymphocytes, and neutrophils even after administration of $10 \mathrm{mg} / \mathrm{kg}$ of cat-USPIOs. These results are consistent with those reported by Ali et $\mathrm{al}^{33}$ for magnetic iron oxide nanoparticles embedded in poly(4vinylpyridine) and coated with polyethylene glycol. They caused no effect on the complete blood erythrocytes, leucocytes, platelets, hemoglobin, and hematocrit counts.

The levels of ALT, aspartate aminotransferase, urea, and creatinine in the blood and urine collected along 28 days are shown in Figure 6. Those parameters were used to evaluate the toxic effects of cat-USPIOs in liver and kidneys of Wistar rats. There was no significant change in saline, vehicle (10 mM acetate buffer $\mathrm{pH} 4.5$ ), control (no magnet), and experimental (with magnet) groups, except for ALT at 21 and 28 days, that still remained in the normal range since the ALT level is considered normal until up to $80 \mathrm{U} / \mathrm{L} .{ }^{34}$ 

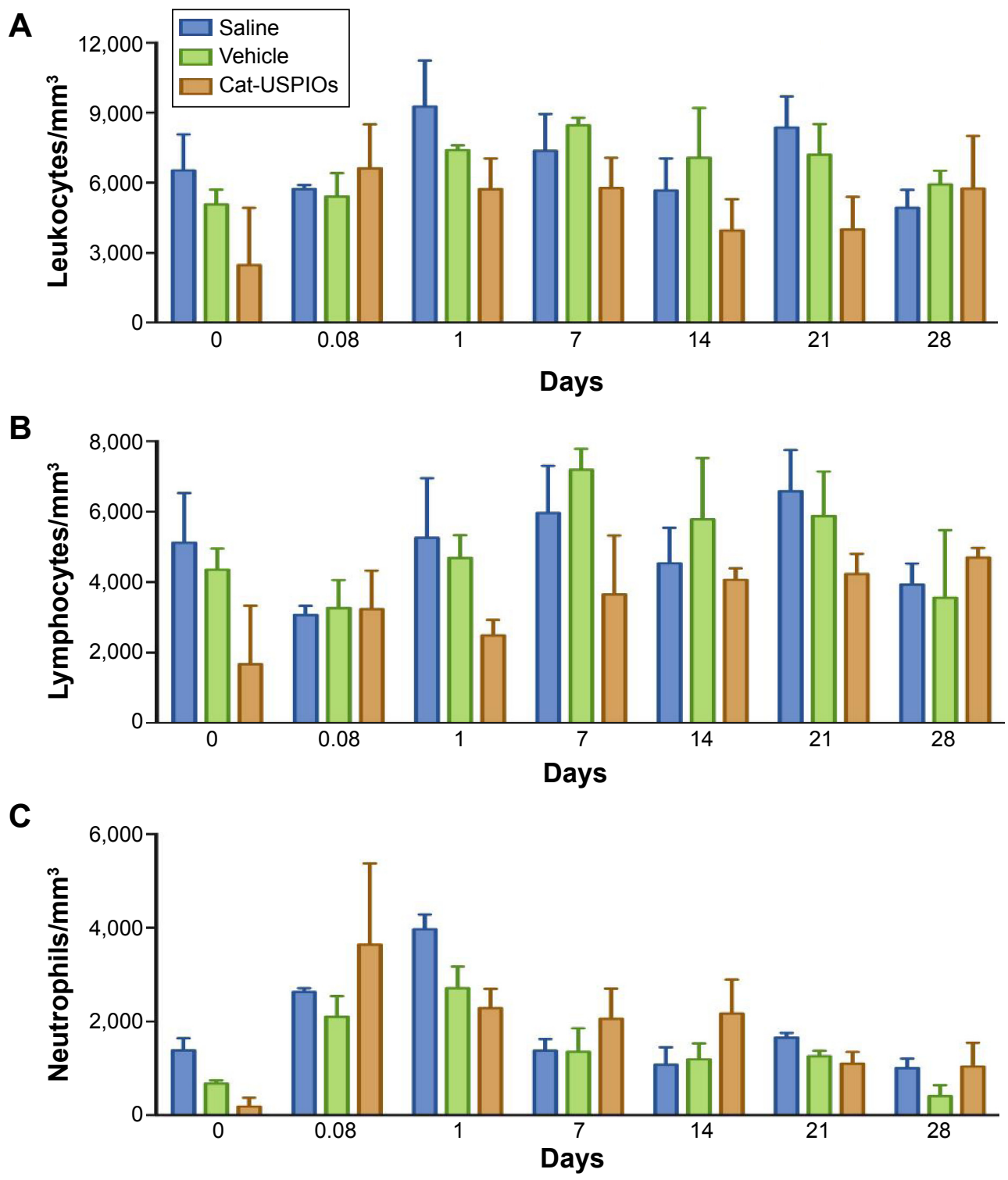

Figure 5 Number of leukocytes (A), lymphocytes (B), and neutrophils (C) present in I $\mathrm{mm}^{3}$ of blood before IV administration (time zero), and as a function of time up to 28 days after IV administration of $10 \mathrm{mg} / \mathrm{kg}$ of cat-USPIOs in Wistar rats $(\mathrm{n}=3)$.

Notes: The controls are saline $(n=3)$ and vehicle solution $(n=3)(10 \mathrm{mM}$ acetate buffer $\mathrm{pH} 4.5)$. No significant statistical difference was observed among the groups. Abbreviations: IV, intravenous; cat-USPIOs, cationic ultrasmall superparamagnetic iron oxide nanoparticles.

In order to confirm those results, in vivo intravital microscopy assays were carried out in the liver microcirculation to obtain a more direct evaluation of eventual toxic effects of cat-USPIOs to that organ. No inflammation (leukocyte adhesion), microhemorrhage, or thrombus formation could be observed in the liver sinusoids, as described in more detail in the following section. Therefore, one can conclude that even high doses of cat-USPIOs do not affect liver functions.

The urine of the group of rats that received $10 \mathrm{mg} / \mathrm{kg}$ of cat-USPIOs, without (control, Figure 7) and with (experimental, Figure 7) a magnet in the left thigh for 2 hours, was collected soon after each MRI measurement and analyzed by GF-AES, a very sensitive analytical technique capable of measuring concentrations down to the nanomolar range. Note that the iron concentration in the urine increased sharply 2 hours after IV administration of cat-USPIOs then decreased steadily down to $50 \mu \mathrm{g} / \mathrm{L}$ in the experimental group (Figure 7), indicating the complete elimination of magnetite nanoparticles after 28 days. A similar behavior was observed for the control group (Figure 7), but the iron level immediately after IV injection (2 hours) was significantly higher than in the experimental group $(528 \mu \mathrm{g} / \mathrm{L}$ as compared to $425 \mu \mathrm{g} / \mathrm{L})$ and remained much higher stabilizing in $200-300 \mu \mathrm{g} / \mathrm{L}$, in contrast with the $50 \mu \mathrm{g} / \mathrm{L}$ achieved in the experimental group.

One should remember at this point that the amount of magnetite nanoparticles concentrated in the liver and spleen 


\section{A}

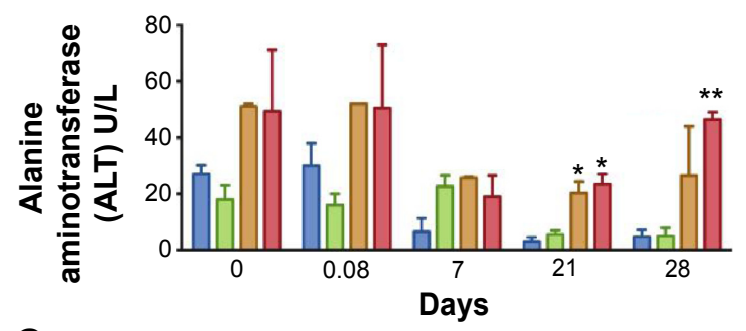

C

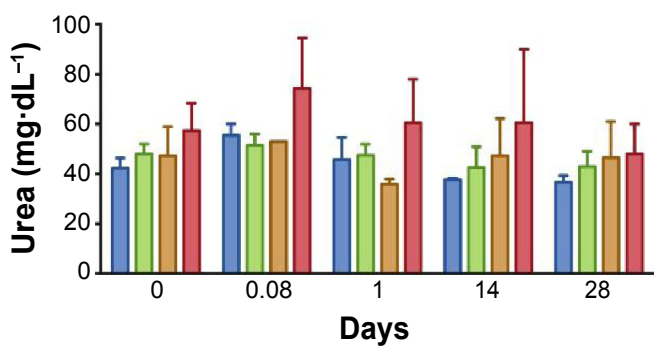

B

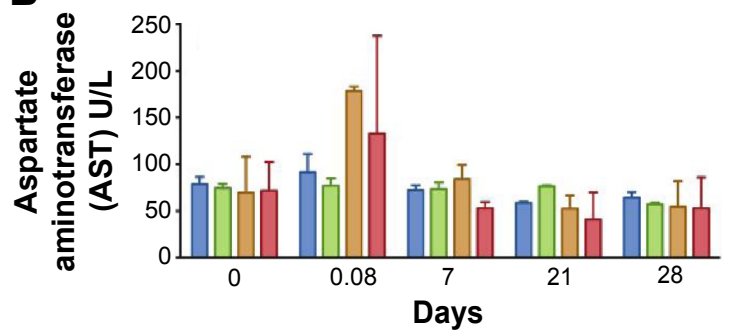

D

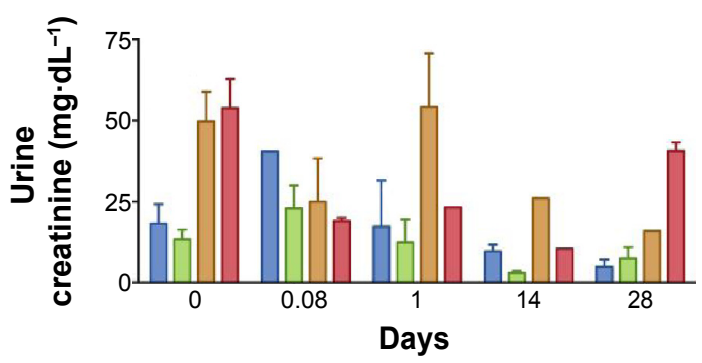

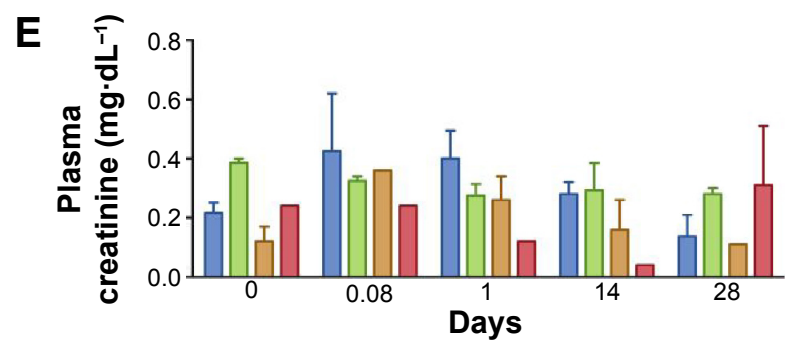

$\square$ Saline $\square$ Vehicle $\square$ Cat-USPIOs without magnet $\square$ Cat-USPIOs with magnet

Figure 6 Kinetic follow-up of blood dosage of hepatic enzymes (A) ALT, (B) AST, (C) urea, and (D) urine and (E) plasma creatinine from Wistar rats treated with 10 mg/kg of cat-USPIOs as a function of time up to 28 days after IV injection.

Notes: A magnet was placed (experimental) or not (control) in the left thigh of a group of rats $(n=3)$ for 2 hours. The controls are saline $(n=3)$ and vehicle solution ( $n=3$ ) ( $10 \mathrm{mM}$ acetate buffer $\mathrm{pH} 4.5)$. $* P<0.05$ and $* * P<0.00$ I versus respective saline treatment.

Abbreviations: cat-USPIOs, cationic ultrasmall superparamagnetic iron oxide nanoparticles; IV, intravenous.

of the control group is much higher than in the experimental group of rats. Also, the clearance rate of cat-USPIOs, magnetically concentrated in the left thigh, was shown to be slower than those retained in the internal organs. Considering

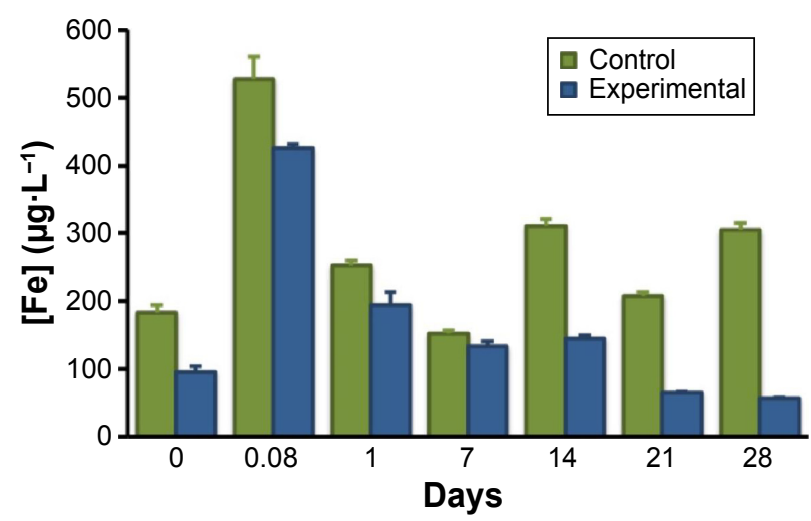

Figure 7 Iron content ([Fe] $\left.\mu \mathrm{g} \cdot \mathrm{L}^{-1}\right)$ determined by GFAAS in the urine of rats $(\mathrm{n}=3)$ as a function of time after intravenous injection of $10 \mathrm{mg} / \mathrm{kg}$ of cat-USPIOs. The experimental group ( $n=3$, blue) has a magnet placed on the left leg thigh for 2 hours in order to concentrate the magnetite nanoparticles, while the control group (green) did not.

Abbreviations: cat-USPIOs, cationic ultrasmall superparamagnetic iron oxide nanoparticles; GFAAS, graphite furnace atomic absorption spectrometer. that liver can effectively get rid of magnetite nanoparticles, probably the extra amount of cat-USPIOs retained by the control group was higher than a critical concentration, ie, saturated its processing capability. Thus, that organ should be working at its maximum capacity along 28 days, until eventually the amount become lower than that limit, and the iron level in urine started to decline exponentially in the same way as in the experimental group (Figure 7). The excess of iron(III) can be eliminated through stool also.

The effect of cat-USPIOs on the microcirculation can be directly evaluated by in vivo fluorescent intravital microscopy as shown in Figure 8A, where dark regions correspond to venules and sinusoids, and yellow regions to hepatic parenchyma labeled with rhodamine 6G. Mesentery and hepatic microcirculation are highly vascularized tissues, widely used to study the toxicity of compounds. No significant difference was observed in the number of adhered leukocytes along the liver sinusoids 3 hours after cat-USPIOs administration as compared with control animals injected saline (Figure 8B). Similarly, no significant difference was observed in the 


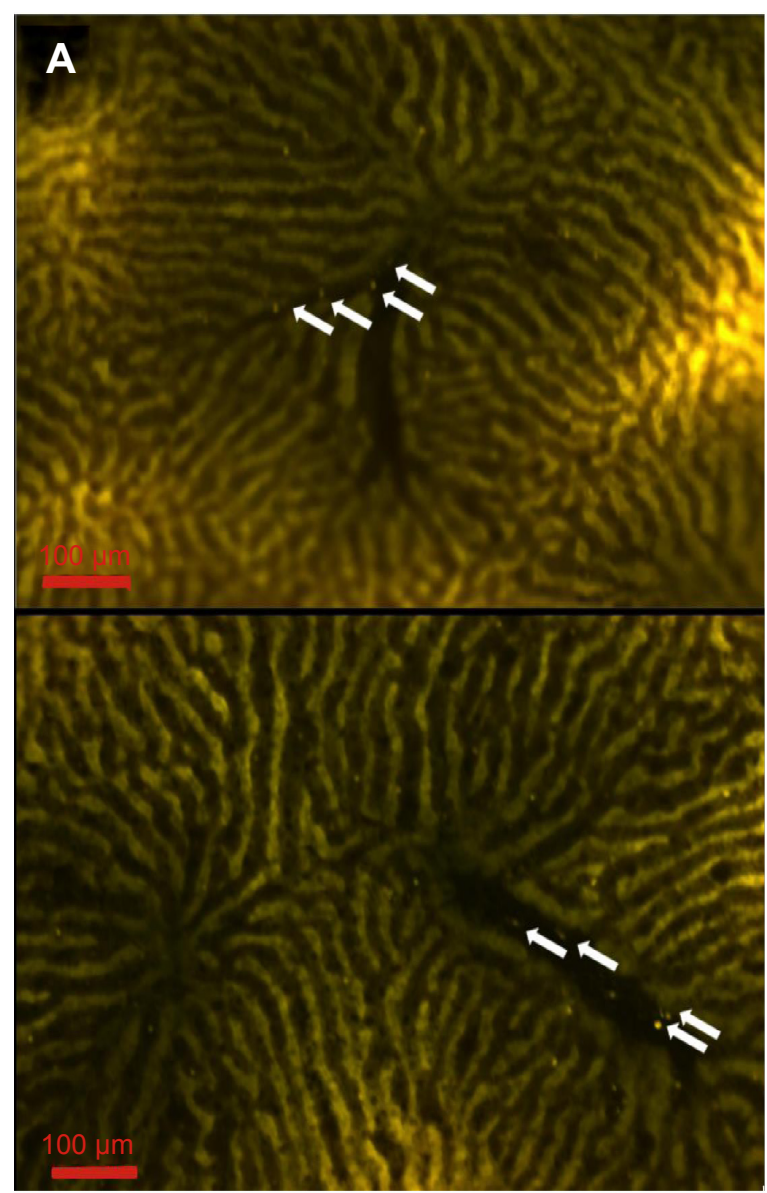

B

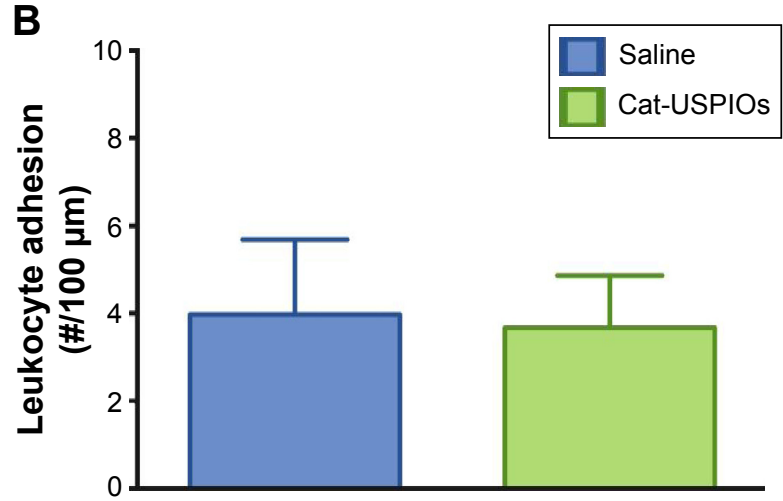

Figure 8 Effect of cat-USPIOs on leukocyte-endothelial interactions evaluated in male Wistar rat liver sinusoids by intravital microscopy.

Notes: (A) Fluorescence intravital microscopy images showing the number of rhodamine 6G-labeled leukocytes adhered to the liver sinusoids 3 hours after intravenous injection ( $1 \mathrm{~mL}$, single dose) of saline (control, above) and $10 \mathrm{mg} / \mathrm{kg}$ cat-USPIOs suspension (experimental, below). (B) Average number of adhered leukocytes in $100 \mu \mathrm{m}$ segments of sinusoid walls considering at least five sinusoids per rat. White arrows indicate adhered leukocytes. Bar $=100 \mu \mathrm{m}$.

Abbreviation: cat-USPIOs, cationic ultrasmall superparamagnetic iron oxide nanoparticles.

number of rolling leukocytes along the vascular endothelial pavement of mesenteric venules after injection of cat-USPIOs, as compared with animals injected saline (Figure S2A). The number of adhered and migrated leukocytes in the mesentery microcirculation increased significantly 30 and
60 minutes after tissue exposure, but a similar behavior was observed in the controls injected saline (Figure S2B and C), evidencing no significant toxicity induced by cat-USPIOs. Also, the venular diameter remained within 20 and $24 \mu \mathrm{m}$ (Figure S2D) evidencing again the low or no toxicity of catUSPIOs to the vascular system. In conclusion, the intravital microscopy assays confirmed the safety of cat-USPIOs since important toxic events such as leukocyte activation, thrombus formation or change in vascular diameter were not observed in liver and mesentery vascular bed after IV injection. The negligible tendency of cat-USPIOs to interact with negatively charged cell membranes in the microcirculation may be an indicative of formation of a protective corona of serum proteins, probably albumin, immunoglobulin, and fibrinogen. ${ }^{35}$

\section{Conclusion}

Ethylamine-functionalized, fully dispersible, $7 \mathrm{~nm}$ diameter cat-USPIOs were shown to be nontoxic and very efficient MRI contrast agents. IV administered cat-USPIOs circulate freely throughout the vascular system without retention in organs and tissues, except for liver, kidneys and bladder, responsible for the elimination of foreign substances from body. Cat-USPIOs was cleared from kidneys and bladder of Wistar rats in few days whereas the complete elimination from the body occurred only after 4 weeks. However, the clearance time is dose-dependent. Also, quite low in vivo toxicity was observed. In fact, they caused no effect on the number of leukocytes, lymphocytes, and neutrophils, as well as in the levels of ALT, aspartate aminotransferase, urea, and plasma creatinine, in the blood and urine along 28 days. The in vivo studies by intravital microscopy confirmed their low toxicity as demonstrated by no observable effects on the number of adhered leukocytes, microhemorrhages, and thrombus, as well as on the diameter of microvessels. The lack of interaction of cat-USPIOs with the blood vessel walls suggests they are interacting with biomolecules present in the blood, generating a corona as well as just enough agglomeration to allow magnetic induced concentration. The high relaxivity and insignificant acute/subchronic toxicity make them potential candidates for the development of diagnostic and treatment (theranostics) tools for several diseases.

\section{Acknowledgments}

The authors would like to thank Prof Dr Edivaldo Sabadini and Dr Delmarcio Gomes da Silva for the measurement of cat-USPIOs relaxivity, as well as the financial support granted by Fundação de Amparo a Pesquisa do Estado de São Paulo (FAPESP 2009/08584-6), Conselho Nacional de Desenvolvimento Científico e Technológico (CNPq), and 
Petrobras. MKU and ALBS are doctoral fellows (projects 2010/50072-0 and 2011/09677-8, respectively), and SFR is a postdoctoral fellow (2011/02438-8) of FAPESP.

\section{Disclosure}

The authors report no conflicts of interest. The authors alone are responsible for the content and writing of this paper. The authors have no relevant affiliations or financial involvement with any organization or entity with a financial interest in or financial conflict with the subject matter or materials discussed in the manuscript. This includes employment, consultancies, honoraria, stock ownership or options, expert testimony, grants or patents received or pending, or royalties. No writing assistance was utilized in the production of this manuscript.

\section{References}

1. Reddy LH, Arias JL, Nicolas J, Couvreur P. Magnetic nanoparticles: design and characterization, toxicity and biocompatibility, pharmaceutical and biomedical applications. Chem Rev. 2012;112(11):5818-5878.

2. Das M, Mishra D, Dhak P, et al. Biofunctionalized, phosphonategrafted, ultrasmall iron oxide nanoparticles for combined targeted cancer therapy and multimodal imaging. Small. 2009;5(24):2883-2893.

3. Durdureanu-Angheluta A, Uritu CM, Coroaba A, et al. Heparin-anthranoid conjugates associated with nanomagnetite particles and their cytotoxic effect on cancer cells. J Biomed Nanotechnol. 2014;10(1):131-142.

4. Lee KJ, An JH, Chun JR, et al. In vitro analysis of the anti-cancer activity of mitoxantrone loaded on magnetic nanoparticles. J Biomed Nanotechnol. 2013;9(6):1071-1075.

5. Licciardi M, Scialabba C, Cavallaro G, et al. Cell uptake enhancement of folate targeted polymer coated magnetic nanoparticles. J Biomed Nanotechnol. 2013;9(6):949-964.

6. Alexiou C, Tietze R, Schreiber E, et al. Cancer therapy with drug loaded magnetic nanoparticles - magnetic drug targeting. J Magn Magn Mater. 2011;323(10):1404-1407.

7. Sivakumar B, Aswathy RG, Sreejith R, et al. Bacterial exopolysaccharide based magnetic nanoparticles: a versatile nanotool for cancer cell imaging, targeted drug delivery and synergistic effect of drug and hyperthermia mediated cancer therapy. J Biomed Nanotechnol. 2014; 10(6):885-899.

8. Lopez-Cebral R, Martin-Pastor M, Seijo B, Sanchez A. Progress in the characterization of bio-functionalized nanoparticles using NMR methods and their applications as MRI contrast agents. Prog Nucl Mag Res Spectrosc. 2014;79:1-13.

9. Liu XL, Fan HM. Innovative magnetic nanoparticle platform for magnetic resonance imaging and magnetic fluid hyperthermia applications. Curr Opin Chem Biol. 2014;4(0):38-46.

10. Peng XH, Qian X, Mao H, et al. Targeted magnetic iron oxide nanoparticles for tumor imaging and therapy. Int J Nanomedicine. 2008; 3(3):311-321.

11. Huang J, Zhong X, Wang L, Yang L, Mao H. Improving the magnetic resonance imaging contrast and detection methods with engineered magnetic nanoparticles. Theranostics. 2012;2(1):86-102.

12. Condomitti U, Silveira AT, Condomitti GW, et al. Silver recovery using electrochemically active magnetite coated carbon particles. Hydrometallurgy. 2014;147-148(0):241-245.

13. Jain TK, Reddy MK, Morales MA, Leslie-Pelecky DL, Labhasetwar V. Biodistribution, clearance, and biocompatibility of iron oxide magnetic nanoparticles in rats. Mol Pharm. 2008;5(2):316-327.

14. Uchiyama MK, Deda DK, Rodrigues SF, et al. In vivo and in vitro toxicity and anti-inflammatory properties of gold nanoparticle bioconjugates to the vascular system. Toxicol Sci. 2014;142(2):497-507.
15. Wu X, Tan Y, Mao H, Zhang M. Toxic effects of iron oxide nanoparticles on human umbilical vein endothelial cells. Int J Nanomedicine. 2010;5:385-399.

16. Marcu A, Pop S, Dumitrache F, et al. Magnetic iron oxide nanoparticles as drug delivery system in breast cancer. Appl Surf Sci. 2013;281(0): $60-65$.

17. Sun Z, Yathindranath V, Worden M, et al. Characterization of cellular uptake and toxicity of aminosilane-coated iron oxide nanoparticles with different charges in central nervous system-relevant cell culture models. Int J Nanomedicine. 2013;8:961-970.

18. Barrefelt A, Saghafian M, Kuiper R, et al. Biodistribution, kinetics, and biological fate of SPION microbubbles in the rat. Int J Nanomed. 2013;8:3241-3254.

19. Kumar M, Singh G, Arora V, et al. Cellular interaction of folic acid conjugated superparamagnetic iron oxide nanoparticles and its use as contrast agent for targeted magnetic imaging of tumor cells. Int $J$ Nanomed. 2012;7:3503-3516.

20. Zuin A, Novak MA, Toma SH, Araki K, Toma HE. Anisotropic magnetic carbon materials based on graphite and magnetite nanoparticles. Carbon. 2014;77(0):600-606.

21. Toma SH, Santos JJ, Araki K, Toma HE. Pushing the surface-enhanced Raman scattering analyses sensitivity by magnetic concentration: a simple non core-shell approach. Anal Chim Acta. 2015;855(0):70-75.

22. Caruntu D, Caruntu G, Chen Y, et al. Synthesis of variable-sized nanocrystals of $\mathrm{Fe} 3 \mathrm{O} 4$ with high surface reactivity. Chem Mater. 2004; 16(25):5527-5534.

23. Fortes ZB, Farsky SP, Oliveira MA, Garcia-Leme J. Direct vital microscopic study of defective leukocyte-endothelial interaction in diabetes mellitus. Diabetes. 1991;40(10):1267-1273.

24. Romanowsky I, Lismer L, Asali M, Rosenberg E, Kaneti J. Percutaneous nephrolithotomy for pediatric renal calculus disease: 5 years of local experience. Arch Ital Urol Androl. 2008;80(2):56-58.

25. Haun JB, Yoon TJ, Lee H, Weissleder R. Magnetic nanoparticle biosensors. Wiley Interdiscip Rev Nanomed Nanobiotechnol. 2010;2(3): 291-304.

26. Wang J, Chen Y, Chen B, et al. Pharmacokinetic parameters and tissue distribution of magnetic $\mathrm{Fe}(3) \mathrm{O}(4)$ nanoparticles in mice. Int $J$ Nanomedicine. 2010;5:861-866.

27. Xu H, Song T, Bao X, Hu L. Site-directed research of magnetic nanoparticles in magnetic drug targeting. J Magn Magn Mater. 2005;293(1): 514-519.

28. Allkemper T, Bremer C, Matuszewski L, Ebert W, Reimer P. Contrastenhanced blood-pool MR angiography with optimized iron oxides: effect of size and dose on vascular contrast enhancement in rabbits. Radiology. 2002;223(2):432-438.

29. Briley-Saebo K, Bjornerud A, Grant D, et al. Hepatic cellular distribution and degradation of iron oxide nanoparticles following single intravenous injection in rats: implications for magnetic resonance imaging. Cell Tissue Res. 2004;316(3):315-323.

30. Taqaddas A. Use of magnetic nanoparticles in cancer detection with MRI. Int J Med Health Pharm Biomed Eng. 2014;93:596-604.

31. Thomsen LB, Linemann T, Pondman KM, et al. Uptake and transport of superparamagnetic iron oxide nanoparticles through human brain capillary endothelial cells. ACS Chem Neurosci. 2013;4(10):1352-1360.

32. Jayapaul J, Hodenius M, Arns S, et al. FMN-coated fluorescent iron oxide nanoparticles for RCP-mediated targeting and labeling of metabolically active cancer and endothelial cells. Biomaterials. 2011;32(25): $5863-5871$.

33. Ali LM, Gutierrez M, Cornudella R, et al. Hemostasis disorders caused by polymer coated iron oxide nanoparticles. J Biomed Nanotechnol. 2013;9(7):1272-1285.

34. Johnson-Delaney CA, DVM, ABVP-Avian D. Exotic Companion Medicine Handbook. Kirkland, Washington, DC: Zoological Education Network; 2008.

35. Lind K, Kresse M, Muller RH. Comparison of protein adsorption patterns onto differently charged hydrophilic superparamagnetic iron oxide particles obtained in vitro and ex vivo. Electrophoresis. 2001;22(16): 3514-3521. 


\section{Supplementary materials}

Comparison of rats treated with $10 \mathrm{mg} / \mathrm{kg}$ of cat-USPIOs in the presence and absence of a magnet in the left thigh

The suitability of ethylamine-functionalized cationic ultrasmall superparamagnetic iron oxide nanoparticles (catUSPIOs) as magnetic resonance imaging (MRI) contrast agent after intravenous (IV) administration of $50 \mathrm{mg} / \mathrm{kg}$ body weight of them dispersed in $1 \mathrm{~mL}$ of acetate buffer $(10 \mathrm{mM}$ $\mathrm{pH} 4.5$ ) containing $50 \mathrm{mM}$ of $\mathrm{NaCl}$ was described in the manuscript. The same procedures used in those experiments were adopted here, but administering a lower dose of $10 \mathrm{mg} / \mathrm{kg}$ body weight in control (without a magnet) and experimental (with a magnet in the left thigh) groups, in order to compare the efficiency as MRI contrast and the clearance time. The MRI images were collected from about 2 hours up to 28 days after IV administration.

The contrast at liver and kidneys of control group of Wistar rats started to become brighter 14 days and 1 day (Figure S1A) after administration, respectively, whereas the same started to happen with the experimental group after 7 days and 2 hours (Figure S1B). This result was confirmed by following the density of white pixels in MRI, where the experimental group exhibited higher density than the control group. This result was expected since in the controls, the total amount of cat-USPIOs was just distributed to liver, spleen, and kidneys, whereas a significant amount was retained in the thigh by a magnet in the experimental group. Considering the fact that this magnetically concentrated nanoparticles are cleared more slowly than those accumulated in the internal organs, and that all experimental conditions are identical except for the magnet, it is possible to conclude that the clearance time from the internal organs is dose-dependent. In other words, the clearance rate is dependent on the dose of cat-USPIOs.

\section{Intravital microscopy of rat mesentery: leukocyte-endothelium interactions}

Male Wistar rats (about $200 \mathrm{~g}$ ) were treated with saline $(0.9 \% \mathrm{NaCl})$ and $10 \mathrm{mg} / \mathrm{kg}$ cat-USPIOs. After subcutaneous anesthesia and subsequent insertion of a cannula into the left femoral vein, a single $1 \mathrm{~mL}$ dose of each treatment was administered IV at an infusion rate of $500 \mu \mathrm{L} / \mathrm{min}$.

Medial laparotomy was carried out and the mesentery exposed for in situ microscopic examination according to Zweifach. ${ }^{1}$ The protocols described by Macedo et $\mathrm{al}^{2}$ and de Lima et $\mathrm{al}^{3}$ were employed for animal surgery and the maintenance of mesentery microcirculation. Data were collected before, just after, and every 30 minutes (until up to 2 hours) after injection. Three different vessels were evaluated and averaged for each animal to avoid sampling associated variability.

Injection of cat-USPIOs caused no change in the number of rolled, adhered, and migrated leukocytes (Figure S2A-C), as compared to the saline control, within 2 hours of observation. No significant difference was observed in the venular diameter $(\mu \mathrm{m})$ measured under the same conditions and time (Figure S2D).
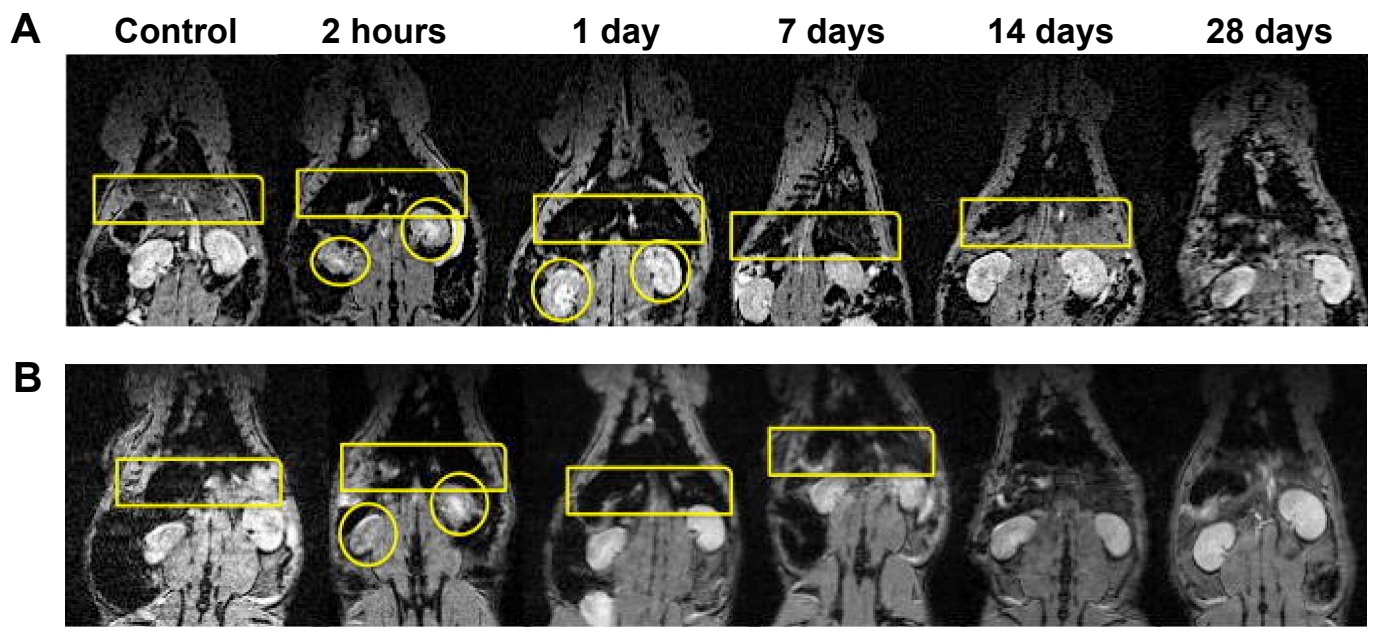

Figure SI MRI monitoring the chest of a male Wistar rat just before (control), and 2 hours, I, 7, I4, and 28 days after IV administration of I0 mg/kg of cat-USPIOs. Notes: Images from (A) the control group (without a magnet) and (B) the experimental group (with a magnet in the left thigh). A yellow rectangle indicates the region where the liver and the spleen are localized while yellow circles indicate the kidneys.

Abbreviations: MRI, magnetic resonance imaging; IV, intravenous; cat-USPIOs, cationic ultrasmall superparamagnetic iron oxide nanoparticles. 
A

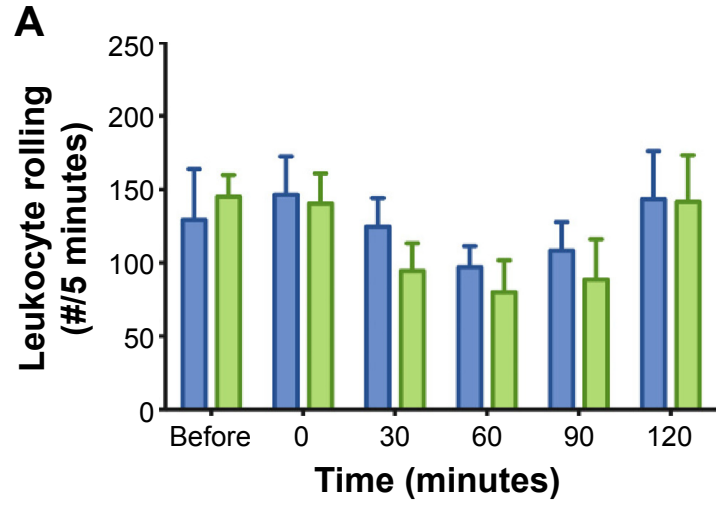

C

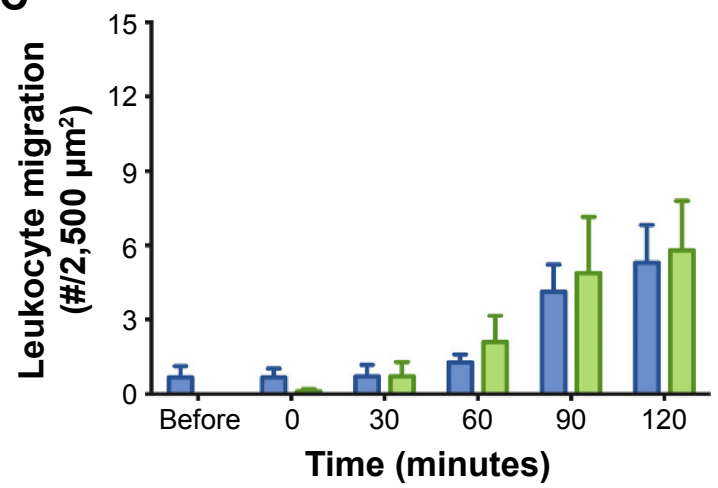

B

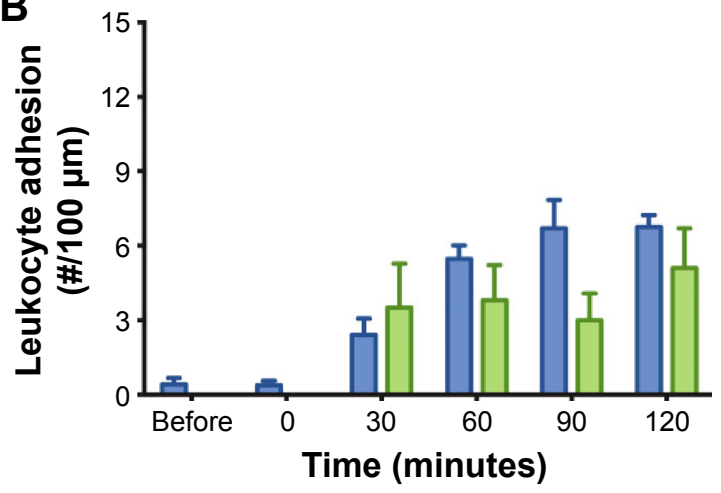

D

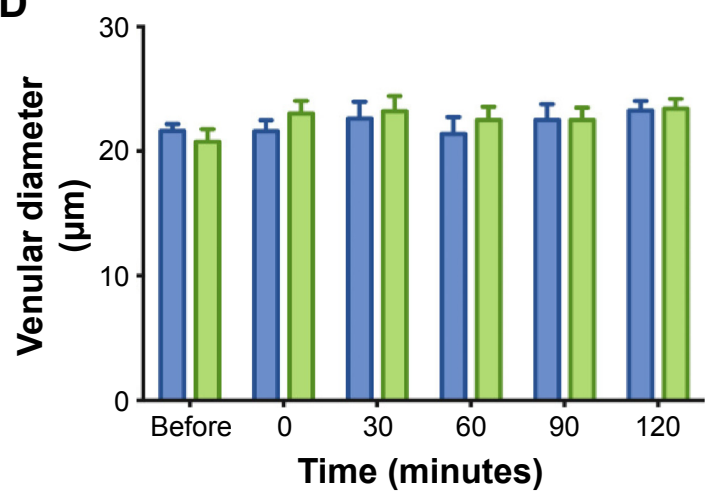

Saline (n=4) [ Cat-USPIO (n=5)

Figure S2 Effect of cat-USPIOs on leukocyte-endothelium interactions evaluated in male Wistar rat mesentery microcirculation by intravital microscopy.

Notes: Number of $(\mathbf{A})$ rolled, (B) adhered, and (C) migrated leukocytes along the mesentery vessel walls before and 30-120 minutes after treatment. (D) Venular diameter $(\mu \mathrm{m})$ measured under the same conditions and time. Values express the average data obtained from 4 to 7 animals in each group. No significant difference was observed. Abbreviation: cat-USPIOs, cationic ultrasmall superparamagnetic iron oxide nanoparticles.

\section{References}

1. Daldrup HE, Link TM, Blasius S, et al. Monitoring radiation-induced changes in bone marrow histopathology with ultra-small superparamagnetic iron oxide (USPIO)-enhanced MRI. J Magn Reson Imaging. 1999;9(5):643-652.

2. Zweifach BW. Microscopic observations of circulation in rat mesoappendix and dog omentum; use in study of vasotropic substances. Methods Med Res. 1948;1:131-139.
3. Macedo SM, Lourenco EL, Borelli P, et al. Effect of in vivo phenol or hydroquinone exposure on events related to neutrophil delivery during an inflammatory response. Toxicology. 2006;220(2-3):126-135.

4. de Lima CB, Tamura EK, Montero-Melendez T, et al. Actions of translocator protein ligands on neutrophil adhesion and motility induced by G-protein coupled receptor signaling. Biochem Biophys Res Commun. 2012;417(2):918-923.

\section{Publish your work in this journal}

The International Journal of Nanomedicine is an international, peerreviewed journal focusing on the application of nanotechnology in diagnostics, therapeutics, and drug delivery systems throughout the biomedical field. This journal is indexed on PubMed Central, MedLine, CAS, SciSearch ${ }^{\circledR}$, Current Contents ${ }^{\circledR} /$ Clinical Medicine,
Journal Citation Reports/Science Edition, EMBase, Scopus and the Elsevier Bibliographic databases. The manuscript management system is completely online and includes a very quick and fair peer-review system, which is all easy to use. Visit http://www.dovepress.com/ testimonials.php to read real quotes from published authors. 